\title{
A Prospective Study Comparing The Functional Outcome, Radiological Outcome and Gait Analysis between Lateral Surgical Approach and Posterior Surgical Approach in The Total Hip Replacement
}

\author{
Dr.P.Sivakumar \& Prof. E.S.Arivazhagan
}

\section{Introduction}

Total hip replacement refers to replacement of a diseased hip joint with an artificial acetabulum and head of femur. It is indicated for arthritis of the hip joint and fracture neck of femur. The extraordinary success of total hip replacements has led to a progressive increase in the number of replacement surgeries done. The clinical research towards various components of hip replacement has led to rapid development but the choice of approach remains surgeon dictated.

The primary aim of total hip arthroplasty is to create a stable, functional and painless hip. The success of total hip arthroplasty depends on the ability of the surgeon to achieve adequate surgical exposure and minimizing complications so as to achieve optimal implant position.

Now a days, the most widely performed approaches for the total hip replacement are the abductor muscle splitting lateral approach and the posterior approach.

There is a difference of opinion among orthopaedic surgeons regarding the best surgical approach for total hip replacement. The proponents of the posterior approach claim better exposure, less blood loss and easy implant positioning without abductor damage but the proponents of lateral approach site a lower rate of dislocation.

As in literature, none of the studies have provided conclusive evidence on the superiority of one approach over the other, the best approach for a surgeon would be the one that he is very familiar with.

\section{Aims and Objectives}

The objective of the present study is to analyse the Functional outcome, Radiological outcome and Gait in patients, who underwent total hip replacement through lateral surgical approach and posterior surgical approach The aim of the study is to prospectively compare the Functional outcome, Radiological outcome and Gait analysis between lateral surgical approach and posterior surgical approach in total hip replacement.

\section{Biomechanics}

It is important to know the biomechanics of the hip joint as the factors which affect the hip must be understood to prevent the complication and further deterioration of the hip joint.

For the better understanding of the forces that act on the hip, the weight of the body has been compared to a load that is applied to a lever arm that extends from the centre of gravity of the body to the centre of the head of the femur. The abductor muscle force, which acts on a lever arm that extends from the centre of the head of the femur to the lateral part of the greater trochanter, will exert a greater moment to tilt the pelvis, while walking and running, to the same side and an equal moment to hold the pelvis level, when in a one-legged stance. As the "ratio of the length of the lever arm of the body weight to that of the abductor musculature is approximately 2.5: 1 , the force of the abductor muscles must approximate 2.5 times the body weight while maintaining the pelvis at level when standing on one leg. The estimated load on the on the head of the femur during the stance phase of gait is equal to the sum of the forces created by the abductor musculature and the weight of the body and is at least thrice the body weight. The load on the femoral head during straight leg raising is also estimated to be the same ${ }^{[1,2,3]}$."

The forces on the hip joint act in the coronal plane and also in the sagittal plane to bend the stem posteriorly, because the center of gravity of the body which is in the midline just anterior to the second vertebral body of the sacrum, is posterior to the hip joint axis. During flexion of the loaded hip, as while ascending and descending stairs,arising from a chair or an incline or lifting, the forces acting in this direction are increased.

Forces against the prosthetic head of the femur are directed from a polar angle between 15 and 25 degrees anterior to the sagittal plane of the prosthesis, during the gait cycle. During straight leg raising and stair climbing, the resulting force is applied at a point even further anterior on the femoral head. Retroversion or 
posterior deflection of the femoral component are caused by such forces.

Hip joint stress may be reduced by changes in the mechanism of the joint, such as leaning on the affected side, increasing the weight- bearing surface of the joint and decreased weight of the patient. Another method of altering the mechanism is the use of a cane on the opposite side. Total hip prosthesis is expected to perform a mechanical function by transmission of weight load and also transmission of motion. Not only must low frictional resistance be maintained between a joint but also the torsional force transmitted from the prosthetic femoral head to the socket must be resisted for a successful arthroplasty.

Prosthetic components of total hip arthroplasty must withstand several years of cyclical loading that is equal to 3 to 5 times the weight of the body and at times 10 to 12 times while jogging and running. Increased physical activity and increased body weight will add to the loosening, and hence hip replacement patient should not do these activities.

\title{
Forces Acting About The Hip
}

Forces acting about the hip need to considered in both the sagittal and coronal planes, in both double and single leg stance.

\section{Double leg stance:}

"In the sagittal plane the centre of gravity is located directly above the centre of the femoral heads. No turning moment is therefore generated about the hip; as a result, no muscular forces are required to maintain equilibrium. If the body leans backwards slightly and the centre of gravity moves posterior with respect to the centre of the femoral head, the anteriorly located iliofemoral ligament becomes taut and helps to maintain equilibrium. In the coronal plane the load of the body weight minus the weight of the legs is distributed equally over the two hip joints, generating equal joint reaction forces(JRF)."

\section{Single leg Stance:}

"When a single-leg stance is adopted, as occurs during walking, the hip joint acts as a fulcrum in a first-class lever system. The hip therefore allows the body to pivot about its centre with respect to the stance leg. If a single leg is considered to be one-sixth of the body weight, then, with single-leg stance, the remaining fivesixths of the body weight generates a turning moment about the hip. In order to maintain balance, the hip abductors (HAs) contract, generating a counter-moment to maintain equilibrium. The length of the lever arm of the HAs is approximately half the length of the lever arm of the body weight. A HA force almost twice the body weight is therefore required to maintain balance. This force, in combination with the body weight, generates a JRF of almost three times the body weight. The JRF is angled at approximately 14 degree towards the midline, exactly following the primary compressive trabeculae of the femoral head. JRFs can be approximately calculated by summing the HA force and five-sixths of the body weight. However, as the HA force is angled at approximately 20 degree with respect to body weight, accurate calculation of the JRF requires resolution of the HA force into its horizontal and vertical vectors. The vertical component of the HA force is then combined with the body weight component as they act in the same direction. Pythagorean theorem can then be used to combine this summed vertical vector with the horizontal vector of the HA force to accurately calculate the JRF."

\section{Biomechanics of Hip Joint}

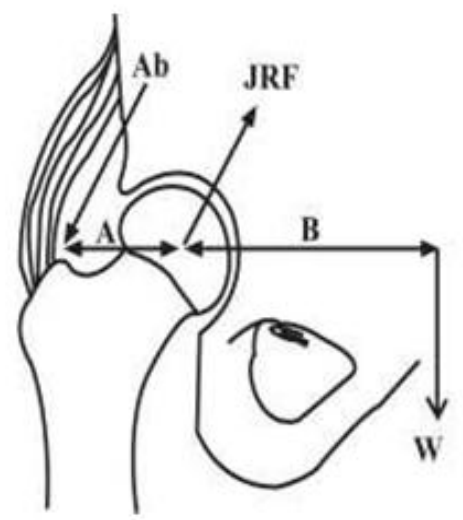

\author{
Ab-Abductor force \\ A - Abductor moment arm \\ B - Moment arm of body weight \\ JRF - Joint reaction force \\ W-Body weight
}

Gait

"Human gait is bipedal, biphasic, forward propulsion of centre ofgravity, in which there is alternate sinuous movement of head and body, with least expenditure of energy". 


\section{Normal walking requirements are}

1. Equilibrium-ability to assume upright posture and maintain balance.

2. Locomotion-ability to initiate and maintain rhythmic stepping.

3. Musculoskeletal integrity-normal bone joint and muscle function.

4. Neurological control-visual, auditory vestibular and sensory motor input

\section{Gait Analysis}

Gait analysis is a Study of human locomotion. Walking consists of a series of gait cycles .A single gait cycle is known as a STRIDE.

\section{Gait Cycle}

A single gait cycle or stride is defined as a period when one foot contacts the ground to when that same foot contacts the ground again.

Each stride has 2 phases - the Stance Phase which occupies $60 \%$ of the gait cycle and the Swing Phase which occupies $40 \%$ of the gait cycle.

\section{Stance Phase of Gait}

When the foot is in contact with the ground.

Stance phase has 5 parts: 1.Initial Contact (Heel Strike) 2.Loading Response (Foot Flat) 3.Midstance 4.Terminalstance (heel raise) 5. Pre-Swing (toe off)

\section{Swing Phase}

When the foot is not contacting the ground. It is the Limb advancement phase. 3 parts of swing phase are: Initial swing, Mid swing and Terminal swing.

\section{Gait Parameters}

Step length Distance between two feet during double limb support. It is measured from the heel of one foot to heel of contralateral foot Stride length -distance one limb travels during the stance and swing phase.

It is measured from the point of foot contact at the beginning of stance phase to the point of contact by the same foot at the end of swing phase Step time-Amount of time used to complete one-step length

Cadence-

Number of steps taken per minute Walking velocity

Distance travelled per minute Actions of the Hip Joint During Gait

\section{Acceleration and Heel Strike}

"Restraining the forward movement of the lower limb occurs during this interval through the eccentric contractions of hamstring and gluteus maximus muscles acting on the hip joint. This restraining action leaves the hip in a flexed position. The gluteus medius and gluteus minimus contract concentricly abducting the reference limb from a weight bearing position. This involves moving the iliac crest of the reference limb away from the midline (abduction). The iliac crest moves instead of the femur because at heel strike, the foot of the reference limb is in contact with the ground and in a weight bearing position. The femur can not move so the muscles act on the iliac crest which can move. Concomitantly, the non weight bearing hip is hiked upward counterbalancing the effect that gravity wants to exert on the non reference limb which is about to attain a non weight bearing position. Without the concentric contraction of the hip abductors on the weight bearing reference limb, the opposite hip would tilt downward making it very difficult to swing the limb forward in order to take a step. This type of gait is called Trendelenburg Gait"

\section{Heel Strike to Mid-stance:}

"The torso is being pulled over the center of the reference limb as the non-reference limb swings forward. This puts the hip in a neutral position without any direct actions of muscles acting on the hip."

\section{Mid-stance to Toe Off:}

"The non-reference limb is in a non weight bearing stage and is swinging forward as a step is taken. This process drags the torso in front of the reference limb forcing the hip joint of the weight bearing reference limb into an extended position. Once again, this occurs without the direct action of the muscles acting on the reference limb." 


\section{Toe Off to Acceleration:}

"During this interval, the reference limb goes from a weight bearing to a non-weight bearing position as the reference limb begins to swing forward ahead of the torso as a step is being taken. Powerful concentric contractions of the hip flexors, mainly the iliopsoas muscle with help from the adductor muscles bring the hip into a position of flexion. The hip adductors also help the swinging limb move in an inward direction.

This enables the foot to be placed under the pelvis rather than in a position that would be parallel with the shoulder."

\section{Review of Literature}

The first surgeon to think that the hip joint could be artificially replaced was Carnochan in 1840 . Mould arthroplasty was first introduced in 1925 by Dr.Marius N Smith-Petersen ${ }^{[4,5]}$ from Boston. He was used reactive synovial like membrane that he found in a piece of glass in the workman's backyard. Dr. Jean Judet along with his brother, Dr. Robert Judet ${ }^{[6]}$ of Paris(1938), tried to replace the arthritic surfaces of the hip joint using an acrylic like material. The first reported Total hip replacement was done in Germany in 1890 by Gluck $^{[7]}$ using ivory ball and socket joint. In 1919, Delbet treated femoral neck fractures using a rubber femoral head. The first hip arthroplasty was performed by Phillip Wiles ${ }^{[8]}$ (1938) .McKee and Farrar ${ }^{[9]}$ of Norwich, used a total hip prosthesis with a metal acetabular cup and the Thompson prosthesis of chromium alloy in 1951. In 1966, Ring ${ }^{[10]}$ used a prosthesis, which consisted of a metal acetabular cup, which was screwed into the pelvis.

By the early 1960s the complications of infections, loosening, poor metallurgy and foreign body reactions were clearly demarcated. The true revolution for these came in 1958, when Charnley ${ }^{[11,12]}$ analysed effective methods of replacing both the head of the femur and acetabulum. After analysing animal joint lubrication he developed a concept of low friction arthroplasty. An important part of Charnley's concept is medialization of cup (centralization of head) and lateralization of trochanter, which increase the length of lever arm of abductor and thereby decreases the force acting on joint which reduces friction and frictional torque and decreases the chances of wear and loosening. But due to his concept subchondral bone at acetabulum is violated which has increased acetabular loosening.

The original technique Charnley ${ }^{[11,12]}$ used was the anterolateral surgical approach with, anterior dislocation of the hipanterior dislocation of the hip and osteotomy of the greater trochanter, with the patient in the supine position. This approach is unpopular among hip surgeons as reattachment of the separated greater trochanter, poised several problems. Amstutz ${ }^{[13]}$ modified the charnly's technique. The difference was that the patient in was placed in the lateral position in this technique and osteotomy of the greater trochanter was done through the anterolateral approach. In the Muller technique, the patient is placed in the lateral position through the anterolateral approach the anterior part of the abductor mechanism only is released.

The role of greater trochanter osteotomy in hip replacement is still a debate among some hip surgeons. Those who advocate trochanteric osteotomy argue that surgical exposure is unsurpassed. It is particularly useful in difficult primary arthroplasties such as acetabular protrusion, stiff hips, hip dysplasia, and posttraumatic cases, as well as in revision arthroplasties Furthermore, advancement of the abductor mechanism during trochanteric reattachment allows adjustment of soft tissue tension after Total Hip Arthroplasty, thereby avoiding instability. The demerits of trochanteric osteotomy aregreater blood loss, increased operating time wound haematoma, delayed postoperative weight bearing, trochanteric bursitis, non union of trochanter and breakage of wire ${ }^{[14]}$

Numerous surgeons have modified the lateral approach. All modifications of this technique for Total Hip Arthroplasty have a common element: the hip is approached through the interval within the gluteus medius muscle and the tensor fascia lata, some portion of the abductor mechanism is released from the greater trochanteric region, and the femoral head is anteriorly dislocated. The various anterolateral approaches differ in the technique recommended to mobilize the abductors from the greater trochanter.

In 1954 McFarland and Osborne ${ }^{[15]}$ introduced “ a new surgical approach to the hip joint. This approach was based on their anatomical observation that the vastuslateralisandgluteus medius were in functional continuity with the thick tendinous periosteum covering the greater

trochanter of the femur. The patient is placed lateral position and the vastus lateral is and gluteus medius are detached from their posterior borders and the combined muscle moved forward like a bucket handle. 
This procedure involves normally detaching thin shell of bone or some spicules of bone from the lateral aspect of the trochanter which is then moved forward."

Hardinge ${ }^{[16]}$ ( 1982) described "a new surgical approach which was based on the anatomical fact that the gluteus medius muscle is inserted in to the greater trochanter by a strong tendon which is wide in its anterior half.

At the junction of the middle and posterior one thirds of the gluteus medius, incision is made in line with the fibers of the muscle. Distally, the incision is made along the anterolateral surface of the femur anteriorly in line with the fibers of the vastus lateralis. The major change described by Hardinge ${ }^{15}$ was to leave the posterior portion of the gluteus medius, with its thickest insertion point, undisturbed from the greater trochanter. Avulsion of the repair of the anterior portion of the abductors or direct injury to the superior gluteal nerve may result in residual abductor weakness and limp following this surgical approach."

In the Dall ${ }^{[17]}$ modification of this approach "anterior portion of the abductors with an attached thin wafer of bone is removed from the anterior edge of the greater trochanter in order to facilitate their later repair. Bony reattachment of the anterior portions of these muscles facilitates better abductor function."

Mallory Frndak in 1993 modified the Hardinge ${ }^{[16]}$ approach "by placing the abductor split more anteriorly and directly over the femoral head and neck of the femur."

Learmonth $^{[18]}$ in 1996 described "a modified lateral approach to the hip which exploits the functional continuity of gluteus medius and vastus lateral is and their dense crescentic attachment to the greater trochanter. The gluteus medius is detached and mobilised with gluteus minimus as one unitand it is not incised or split. This facilitates Gluteireattachment and helps to preserve abductor function.”

The anterolateral approach first described by Bardenhauer and later improved by Watson Jones [19] exposes the hip between the Tensor fascia lataand Gluteus medius interval. After incising superior, anterior and inferior portions of the capsule, hip is dislocated anteriorly. The anterolateral approach is not commonly used now.

The earliest account of a posterior exposure is that of von Langenbeck ${ }^{[20]}$ (1874), "The gluteus maximus muscle was split in the direction of a line extending from the palpable posterior superior iliac spine to the tip of the Trochanter, in line with the fibers of muscle."

The Langenbeck approach had been modified by Kocher ${ }^{[21]}$ in 1907. All Kocher's incisions served the fundamental principle primum non nocere; they were designed to pass between adjacent nerve territories. In the hip joint the tissues were separated between the territories of the superior and inferior gluteal nerves between the gluteusminimus, gluteus medius and tensor fasciae latae on one hand and gluteus maximus on the other. He shifted the approach to anterior border of the greater trochanter and added a distal limb along the line of the shaft of the femur; the upper limb passed obliquely backwards towards the posterior superior spine along or near the upper border of the gluteus maximus. Kocher's approach was designed to improve the exposure of the acetabulum for the treatment of tuberculosis.

Gibson $^{[22]}$ in 1950 modified Kocher's approach. He improved the exposure of the hip by adding release of the two main abductors of the hip namely gluteus medius and minimus muscles.

Moore's approach $^{[23]}$ ( 1959 ) was named "the southern exposure." He divided Gluteus maximus fibres by blunt dissection and cut the short external rotators to expose the capsule. The Gluteus medius is not disturbed by this approach. This is the standard posterior approach most commonly used in practice.

The advantages of the posterior approach ${ }^{[24]}$ are that it is almost bloodless, rapid and attended by less incidence of shock. The tensor fasciae latae and gluteus maximus, which are so important for the hip joint stability, are not weakened and hence the operation causes no instability.

In posterior fracture-dislocations of the hip joint, direct exposure of the site of the injury is gained. When operation is required to secure replacement of a slipped upper femoral epiphysis the posterior part of the joint with the displaced epiphysis is exposed readily. The approach is ideal for exposure of the sciatic nerve in the buttock, and for dealing with injuries of the gluteal arteries. In arthrodesis of the hip joint the anterior flap may be retracted to allow access to the ilium, which may be required for use as a graft, and the field of implantation of the graft is displayed with the least possible trauma.

Roberts et al.(1984),Vicar et al.(1984),Robinson et al.(1980) ${ }^{[25,26,27]}$. reported that the complications following total hip arthroplasty in relation to both approaches are

1. Nerve injuries - sciatic nerve injury is common in posterior approach whereas superior gluteal nerve injury may occur following lateral approach 
2. Heterotropic ossification- commoner with lateral approach when compared with posterior.

3. Dislocation - commoner with posterior approach when compared with lateral approach ${ }^{[25,26,27]}$.

\section{Acetabular Cup Position:}

Dislocation is the dangerous complication of total hip replacement its reported incidence ranges from $0.6 \%-7.0 \%$.Ali Khan, Brakenbury and Reynolds (1981) ${ }^{[28]}$ reported that most common surgical error that leads to dislocation was improperly placed acetabular cup. This supports an earlier statement by Lewinnek et al.(1976) ${ }^{[29]}$ who identified definite association between anterior dislocation and anteversion of the cup. CT scan is the most accurate method of finding the acetabular cup version and inclination following the total hip replacement.

\section{Acetablar Version}

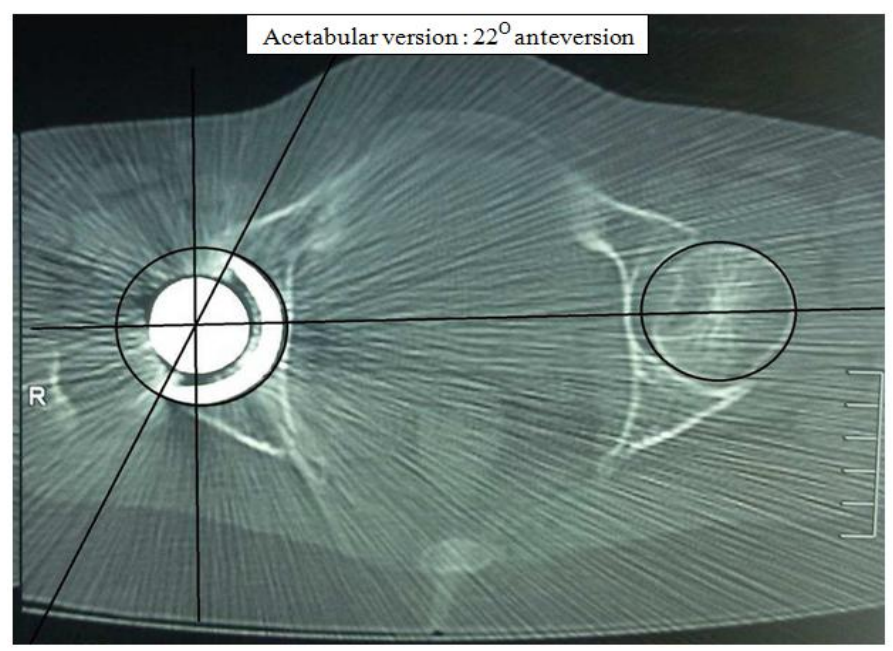

\section{Acetabular Inclination}

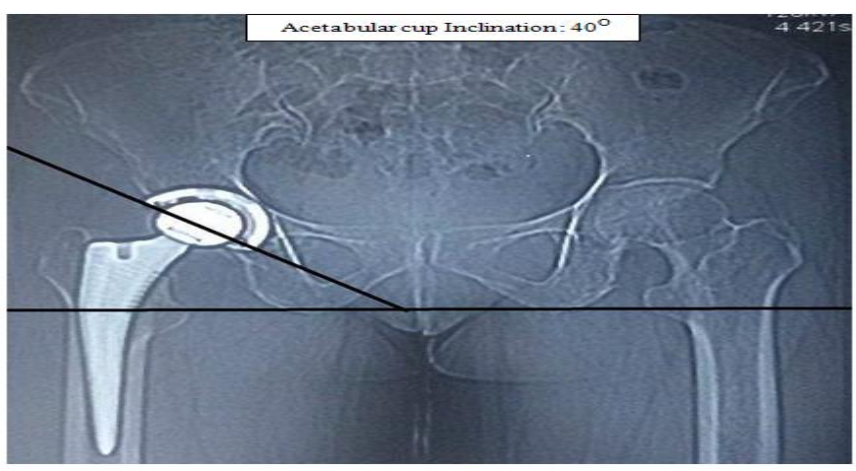

\section{Femoral Offset}

Femoral offset, one of the components of the abductor moment arm, Influences the functions of hip abduction. Increasing the abductor moment arm after total hip arthroplasty has several advantages.

The relationship between the femoral offset or abductor moment arm and other parameters like range of motion, stability of the hip joint and strength of the abductor muscle has been dealt with in many previous reports.

"Greater femoral offset will increase the abductor moment arm and this increase will reduce the abductor force needed for walking."

Definition of femoral offset "The perpendicular distance from the long axis of the femur to the center of rotation of the femur (femoral head center)."

Charnley (1979) ${ }^{[12]}$ considered it to be a factor under the control of the surgeon at the time of hip replacement surgery; the more lateral position of the femur with greater offset was said to increase the range of motion and decrease the incidence of impingement of the femur on the pelvis. An increase in femoral offset (and hence of the lever arm of the abductor muscles) will also, theoretically, increase the strength and 
mechanical advantage of the abductors. Finally, a greater femoral offset will increase stability by improving soft tissue tension and preventing impingement. The surgeon can achieve increased offset during surgery by selecting high offset femoral prostheses and/or a low neck shaft angle prostheses. Surgeons can achieve good biomechanical function of the hip by restoring adequate femoral offset and through proper implant reconstruction $^{[30]}$.

Impingement is either bone on bone or stem on cup. Stem on cup is caused by very small horizontal offset and incorrect matching of the cup and stem position. Incorrect reconstruction of the vertical offset causes bone on bone impingement.

\section{Femoral Offset}

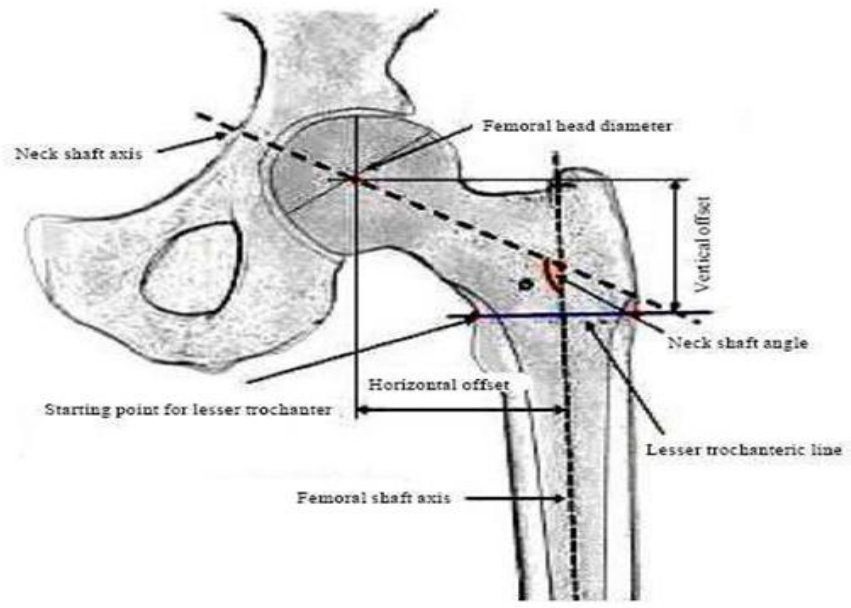

\section{Trendelenburg Test}

Trendelenburg gait is a study of biomechanics and the gluteus medius and minumus muscles. In 1897 Friedrich Trendelenburg described a test which he found useful in determining the hip abductor muscle function integrity, with specific reference to progressive muscular atrophy and congenital dislocation of the hip (Rang 1966). "The examiner observes the angle between the pelvis (the line joining the iliac crests) and the ground while standing behind the patient." Hardcastle and Nade ${ }^{[31]}$ in 1985 described thevarious responses of Trendelenburg test.

During the clinical assessment of patients it is important to do functional assessment of a joint. Because of limitation of space, Observation of the gait is not performed frequently. In a confined space, functional assessment of the hip abductor is done by the Trendelenburg test, and is a much more valuable clinical sign than many other static tests.

In this study we used the response as classified by Dr.V.S.Pai ${ }^{[32]}$ from New Zealand in 1996.

\section{Trendelenburg Test}

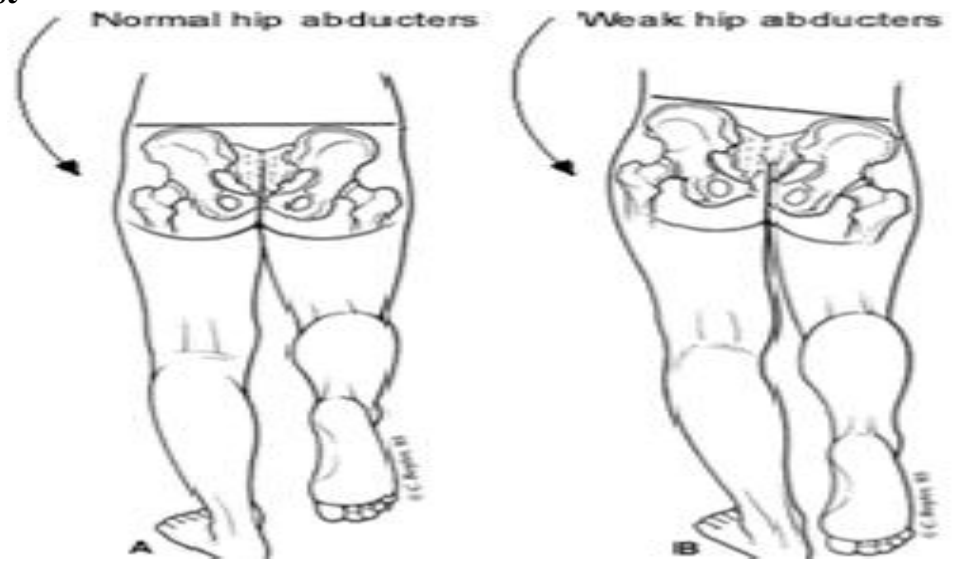




\section{Materials and Methods}

A prospective study was done in patients undergoing total hip replacement from January 2014 to May 2015 in the Institute of orthopaedics and Traumatology, Rajiv Gandhi Government General hospital, Chennai. 20 patients were included in the study out of which 9 were male and 11 were females.

\section{Inclusion Criteria}

1. Age more than twenty years

2. Unstable hip

3. Arthritis hip

\section{Exclusion Criteria}

1. Age less than twenty years

2. Infection

3. Neurological disease or history of sciatica with neurological signs.

4. Revision Total hip arthroplasty 5.Psychiatric illness

Diagnosis included chronic arthritis secondary to primary osteoarthritis, a vascular necrosis, inflammatory conditions namely Ankylosing spondylitis, Rheumatoid arthritis, and non union neck of femur. 10 patients underwent lateral muscle splitting approach and 10 underwent posterior gluteal splitting approach by 2 senior arthroplasty surgeons who have vast experience in the specific surgical approach they perform.

\section{Lateral Approach}

The modified Hardinge ${ }^{[33]}$ approach was used in 10 cases. "For lateral approach, under spinal anaesthesia, patient was positioned in lateral position with the affected side up and stabilised with pubic support. Posteriorly directed lazy-J incision centered over the greater trochanter was made. The fascia lata in line with the skin incision and centered over the greater trochanter was divided. The tensor fasciae latae was retracted anteriorly and the gluteus maximus was retracted posteriorly .Exposing the insertion of the gluteus medius and the origin of the vastus lateralis. The tendon of the gluteus medius was incised obliquely across the greater trochanter leaving the posterior half still attached to the trochanter. The incision carried proximally in line with the gluteus medius fibers at the junction of the anterior and middle One thirds of the muscle. Distally, the incision was carried posteriorly in line with the fibers of the vastus lateralis down to bone along the anterolateral surface of the femur. The tendinous insertions of the anterior portions of the gluteus minimus and vastus lateralis muscles was elevated. The thigh was abducted to expose the anterior capsule of the hip joint. The capsule is incised and hip dislocated. During closure, tendon of the gluteus medius is repaired with non absorbable braided sutures."

\section{Lateral Approach}

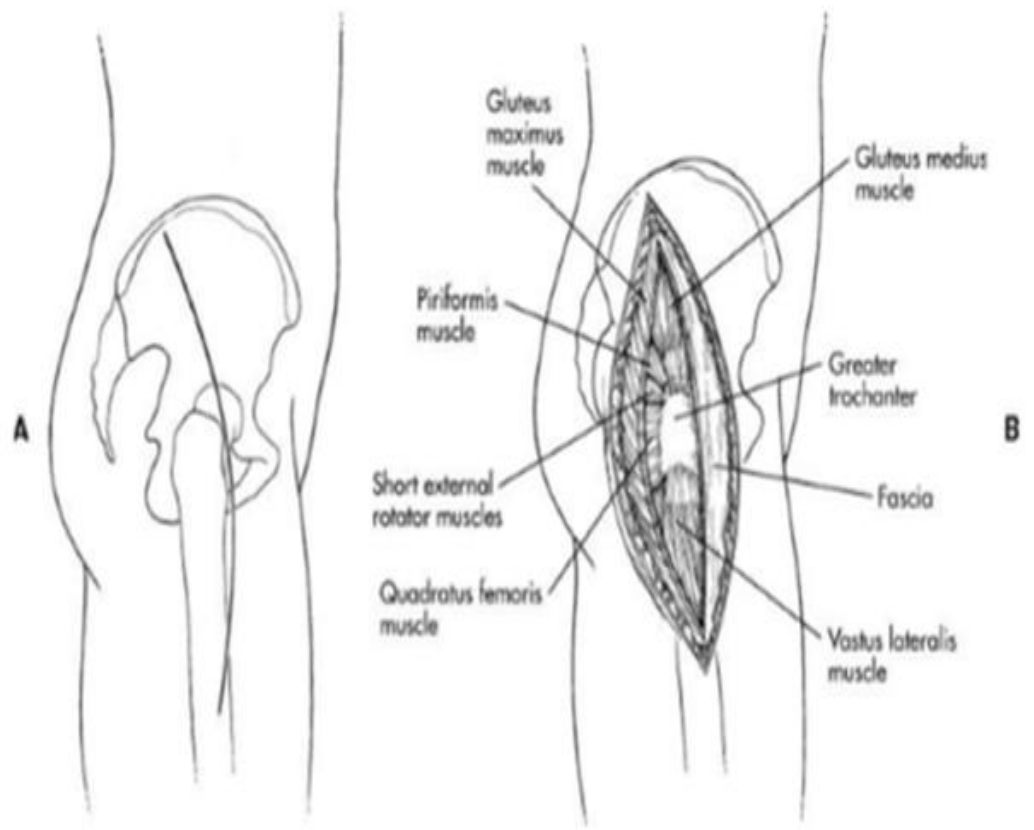




\section{Posterior Approach}

The posterior approach ${ }^{[23]}$ was used in 10 cases. In Posterior approach ${ }^{[23] ~ “ ~ u n d e r ~ s p i n a l ~}$ anaesthesia, patient was positioned in lateral position with the affected side up and stabilised with pubic support. The incision was started approximately $10 \mathrm{~cm}$ distal to the posterior superior iliac spine and extend it distally and laterally parallel with the fibers of the gluteus maximus to the posterior margin of the greater trochanter. Then the incision was directed distally 10 to $13 \mathrm{~cm}$ parallel with the femoral shaft. The deep fascia was exposed and divided in line with the skin incision. Fibers of the gluteus maximus was separated by blunt dissection and care was taken not to disturb the superior gluteal blood vessels in the proximal part of the exposure. The proximal fibers of the gluteus maximus retracted proximally and the greater trochanter exposed. The distal fibers were retracted distally and their insertion into the linea aspera in line with the distal part of the incision was partially divided. Next, the short external rotators were divided at their femoral insertion and the muscles were retracted medially. The posterior part of the joint capsule is now well exposed and was incised it from distal to proximal along the line of the femoral neck of the femur to the rim of the acetabulum. The thigh and knee were flexed at 90 degrees, internally rotated, and the hip was dislocated posteriorly."

\section{Posterior Approach}

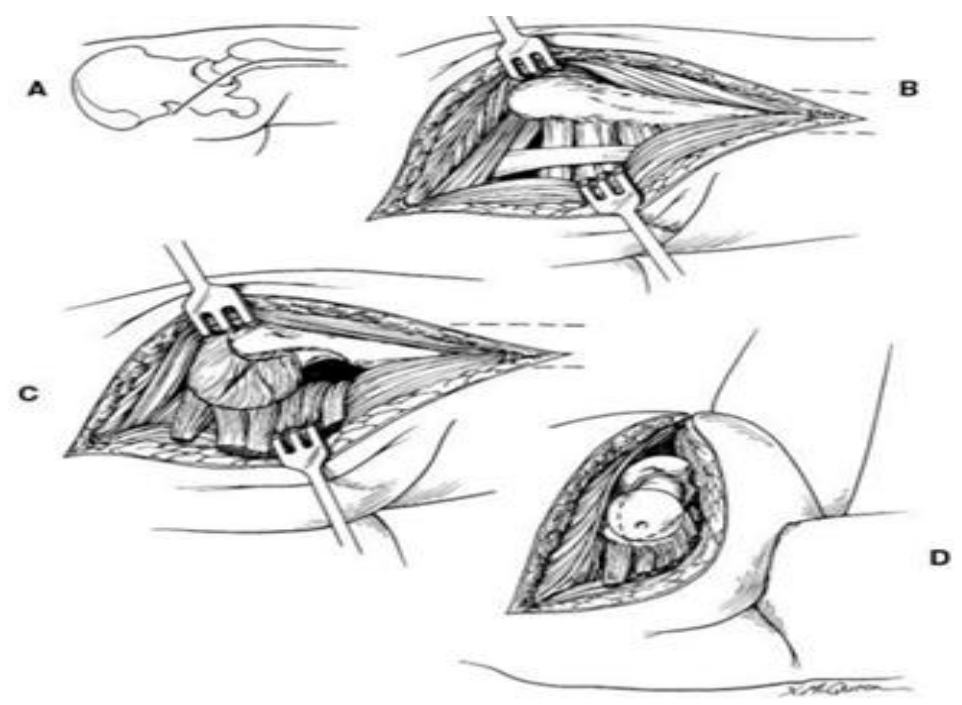

The femur and acetabulum are reamed to appropriate sizes and the prosthesis is inserted. Fixed suture length method was used intraoperatively to assess the correction of limb length discrepancy.

Beginning on the next day morning of surgery, all patients received Low molecular weight heparin and mechanical prophylaxis for thromboembolism in the form of ankle foot pump exercises and calf muscle squeezing. Postoperatively, all patients followed a physical therapy regimen while in bed, including isometric knee extension and hip abduction, beginning on the first postoperative day.

Ambulation also was permitted on the second postoperative Day after drain removal and radiograph. All Patients treated with uncemented arthroplasties were allowed full weight bearing with crutches, beginning on the second postoperative day. Compliance of patients was excellent in all groups. All these patients were examined 3 months postoperatively for assessment.

The functional outcome of hip surgery is assessed using Harris Hip Score (HHS) ${ }^{[34]}$, which has a maximum of 100 points. The domains include pain (44 points), Function (47 points), Deformity (4 points) and Range of motion (5 points).

Function is subdivided into activities of daily living -14 points and gait -33 points.

A Score of 90-100 means excellent results, 80-90 being good, 70-79 fair, and below 70 poor. It is assessed after surgery to determine functional outcome. A Score of 90 to 100 means excellent results, 80 to 90 being good, 70 to 79 fair, and below 70 poor. It is assessed after surgery to determine functional outcome.

\section{Measurement of acetabular version on CT scan}

\section{Radiological Assessment}

In this study we used following methods which were modification from Murray's concept ${ }^{[35]}$, to measure acetabular version. In CT axial view the largest section of the acetabular component was selected. We then drew circles along the margin of the implant or of the acetabulum. To set the true centre of both hips we 
have drawn a first line that connect the centre of both the hip joints and a second line perpendicular to the first. Finally, we drew a third line from the most anterior point of the component to most posterior point. We then measured the angle between the second and third lines and calculated the version. The version from CT scan was regarded as the reference standard for acetabular version ${ }^{[36]}$.

Anteroposterior pelvic and hip radiographs were taken postoperatively with the ankles $20 \mathrm{~cm}$ apart and the feet 15 degrees internally rotated. The horizontal offset and vertical fem ral offset ratio was measured by a single observer from each radiograph. Horizontal femoral offset is "the distance between the centre of rotation of the head of the femur and a line bisecting the long axis of the femur." Vertical femoral offset is "the distance from the centre of rotation of the head of the femur to top of the lesser trochanter."

The femoral offset ratio is deduced by dividing the normal hip joint horizontal and vertical femoral Offset by the replaced hip joint horizontal and vertical femoral Offset. To assess limb length discrepancy, the limb length was measured from the anterior superior iliac spine to the medial malleolus using inch tape. Trendelenburg test was done postoperatively to assess the abductor muscle strength.

In this study we use the response as classified by Dr.V.S.Pai ${ }^{[32]}$ from New Zealand in 1996. According to him, the response is classified as

1. "1. Normal - if the pelvis on the non stance side is elevated high up and maintained for 30 seconds.

2. Elevation of the pelvis on the non stance side present but not maximal

3. Pelvis is elevated on the non stance side but not maintained for 30 seconds

4. No elevation of the pelvis on the non stance side

5. Drooping of the pelvis

6. Non valid response - presence of hip pain, uncooperative patient."

In this study 1 and 2 were considered normal Responses 3, 4, 5 and 6 were considered positive. VISUAL GAIT ANALYSIS was assessed postoperatively using Rivermead visual gait analysis (RVGA) method described by S.E.Lord et al. ${ }^{[37]}$ from Rivermead rehabilitation centre, Oxford, UK IN 1998.

The RVGA comprises " 2 observations of the arms covering both stance and swing of gait, and 18 observations of the trunk and lower limb:

11 observations of the stance phase and 7 of the swing phase of gait. The observations apply to only one side at a time."

"A four-point scale was used to quantify the degree of abnormality for each of the component items: 0 - normal, 1 -mild, 2 -moderate and 3-severe. A global score can be calculated by summing the total numbers of deviation scores, range from 0 (normal gait) to 59 (grossly abnormal gait)."

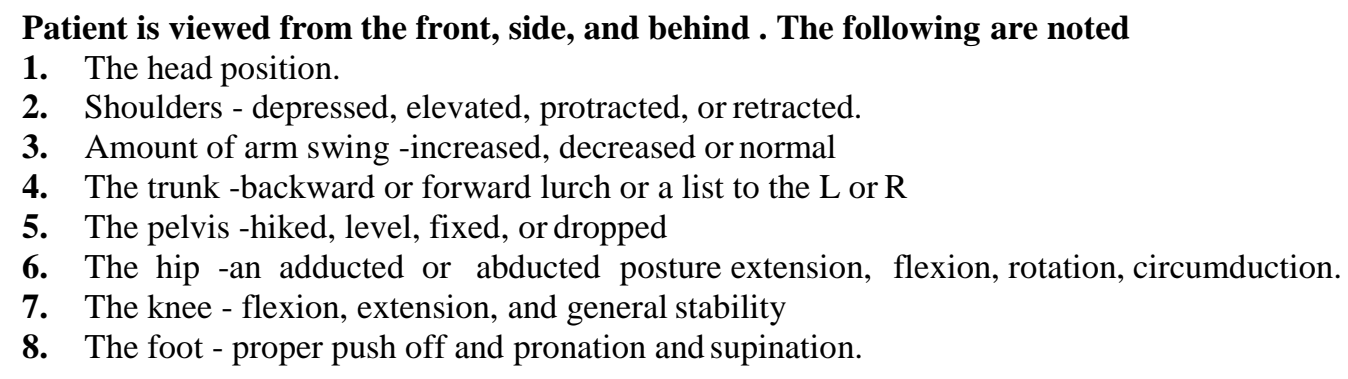

Clinical records from hospital charts were evaluated for complications such as wound drainage, hematoma, dislocation, infection, deep venous thrombosis, pulmonary embolus, neurologic and vascular problems.

All variables in this study were entered into the database and computed using SPSS version 20.0 for windows programme and were analyzed statistically, comparing the posterior approach patients with the lateral approach patients. The statistical analysis involved comparing means of various parameters with resultant $p$ values that are given with $95 \%$ confidence intervals.

\section{Results}

Total hip replacement were performed in 20 patients of which 10 patients underwent Lateral approach ${ }^{[33]}$ and 10 patients underwent posterior approach ${ }^{[23]}$. The mean age was 50.1 years $(27-71)$ in the lateral approach group. The mean age was 52.6 years $(40-70)$ in the posterior approach group. All patients underwent uncemented total hip replacement with same type of implants. In posterior surgical approach group $80 \%$ of patients were $40-60$ years of age, in the lateral approach group $40 \%$ of patients were less than 40 years and $30 \%$ were more than 60 years. 
In posterior surgical approach group $70 \%$ of patients were fmales, $30 \%$ were males and in the lateral approach group $40 \%$ of patients were males and $60 \%$ were females.

Procedure duration was assessed during the surgical procedure in both lateral surgical approach group patients and posterior surgical approach group patients. The mean Procedure duration in posterior approach group was $80 \mathrm{~min}$ and mean Procedure duration in lateral approach group was $110.50 \mathrm{~min}$. The Procedure duration in posterior approach group was shorter than the lateral approach group. It is not statistically significant (P value:0.001).

\section{Procedure Duration}

\begin{tabular}{|l|l|l|l|l|l|l|}
\hline $\begin{array}{l}\text { Procedure } \\
\text { Duration (min) }\end{array}$ & Group & N & Mean & $\begin{array}{l}\text { Std. } \\
\text { Deviation } \\
\text { Mean }\end{array}$ & T-Test P Value \\
& & & & & & \\
& Posterior & 10 & 80.00 & 16.330 & 5.164 & 0.001 \\
\cline { 3 - 7 } & Lateral & 10 & 110.50 & 13.427 & 4.246 & \\
\hline
\end{tabular}

Blood loss was assessed during the surgical procedure in both lateral surgical approach group patients and posterior surgical approach group patients. The mean Blood loss in posterior approach group were $287.0 \mathrm{ml}$ and mean Blood loss in lateral approach group were $308 \mathrm{ml}$.There is less blood loss in posterior approach group than the lateral approach group, eventhough it is not statistically significant (P value:0.571).

\section{Blood Loss}

Limb Length Discrepency was assessed post operatively in both lateral surgical approach group patients and posterior surgical approach group patient clinically. The mean limb length Discrepency in posterior approach group were 0.020 and in lateral approach group were 0.120 .There is better correction of limb length discrepency in posterior approach group than the lateral approach group, even though it is not statistically significant (P value:0.147).

\section{Limb Length Discrepency}

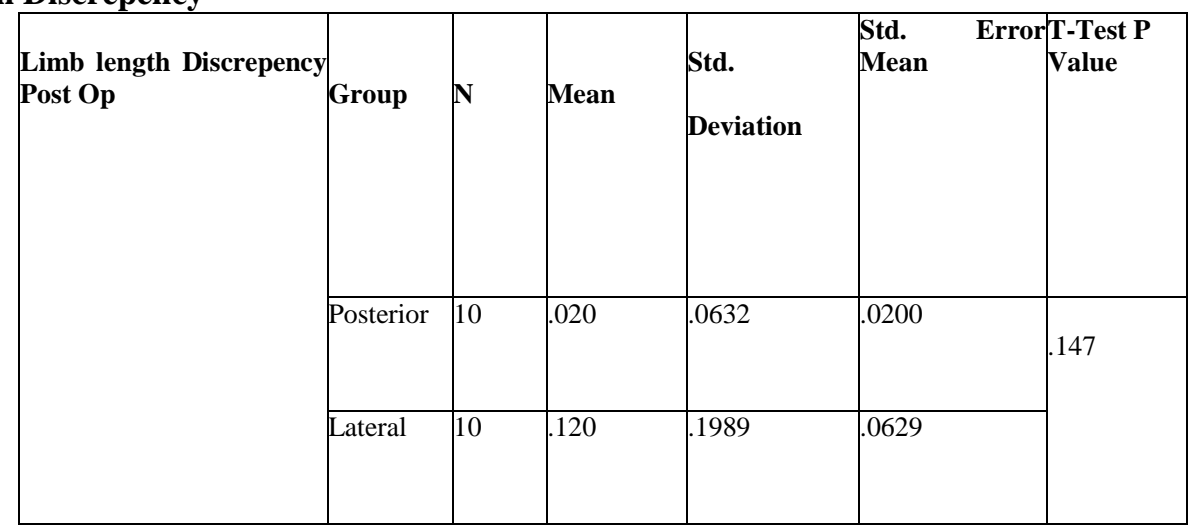

Horizontal and vertical femoral offset ratio were evaluated postoperatively, in both lateral surgical approach group patients and posterior surgical approach group patients using the radiography. The mean Horizontal and vertical femoral offset ratio in posterior approach group were 0.980 and 0.990 respectively and mean Horizontal and vertical femoral offset ratio in lateral approach group were 0.980 and

1.60. Although there is better vertical femoral offset ratio in posterior approach group than the lateral approach group, there is no difference in mean horizontal offset ratio. Although it is not statistically significant. 


\section{Femoral Vertical offset ratio}

\begin{tabular}{|l|l|l|l|l|ll|}
\hline & & & & Std. & Std. & Error T-Test P Value \\
\cline { 2 - 7 } \\
$\begin{array}{l}\text { Femoral Vertical offset } \\
\text { ratio }\end{array}$ & Posterior & 10 & .990 & .0316 & .0100 & .064 \\
& Lateral & 10 & 1.060 & .1075 & .0340 & \\
\hline
\end{tabular}

Femoral Horizontal offset ratio

\begin{tabular}{|c|c|c|c|c|c|c|}
\hline Femoral & HorizontalGroup & $\mathbf{N}$ & Mean & $\begin{array}{l}\text { Std. } \\
\text { Deviation }\end{array}$ & Std. Error Mean & T-Test P Value \\
\hline offset ratio & Posterior & 10 & .980 & .0422 & .0133 & \multirow[t]{2}{*}{1.000} \\
\hline & Lateral & 10 & .980 & .0422 & .0133 & \\
\hline
\end{tabular}

Evaluation of acetabular cup version was performed postoperatively, in both lateral surgical approach group patients and posterior surgical approach group patients using the computerised tomography. The mean acetabular cup version in posterior approach group were 24.50 and mean acetabular cup version in lateral approach group were 27.10. There is better acetabular cup version in posterior approach group than the lateral approach group, eventhough it is not statistically significant (P value : 0.667).

\section{Acetabular Cup Version}

\begin{tabular}{|c|c|c|c|c|c|c|}
\hline \multirow[t]{3}{*}{\begin{tabular}{|l|} 
Acetabular \\
Version
\end{tabular}} & cup Group & $\mathbf{N}$ & Mean & $\begin{array}{l}\text { Std. } \\
\text { Deviation }\end{array}$ & $\begin{array}{l}\text { Std. Error } \\
\text { Mean }\end{array}$ & \begin{tabular}{|l|} 
T-Test \\
Value
\end{tabular} \\
\hline & Posterior & 10 & 24.50 & 13.377 & 4.230 & \\
\hline & Lateral & 10 & 27.10 & 13.195 & 4.173 & .667 \\
\hline
\end{tabular}

Evaluation of acetabular cup inclination was performed postoperatively, in both lateral surgical approach group patients and posterior surgical approach group patients using the computerised tomography. The mean acetabular cup inclination in posterior approach group were 39.50 and mean acetabular cup inclination in lateral approach group were 38.30. There is better acetabular cup inclination in posterior approach group than the lateral approach group, eventhough it is not statistically significant (P value:0.746).

\section{Acetabular Cup Inclination}

\begin{tabular}{|l|l|l|l|l|l|l|}
\hline \multirow{4}{*}{$\begin{array}{l}\text { Acetabularcup } \\
\text { Inclination }\end{array}$} & Group & N & Mean & $\begin{array}{l}\text { Std. } \\
\text { Deviation }\end{array}$ & $\begin{array}{l}\text { Std. Error } \\
\text { Mean } \\
\text { Value }\end{array}$ \\
\cline { 2 - 7 } & Posterior & 10 & 39.50 & 9.789 & 3.096 & \\
\cline { 2 - 6 } & Lateral & 10 & 38.30 & 6.129 & 1.938 & .746 \\
\hline
\end{tabular}

Evaluation of gait was performed at the end of 3 months postoperatively, in both lateral surgical approach group patients and posterior surgical approach group patients. The mean Rivermed gait score in posterior approach group were 2.50 and mean Rivermed gait score in lateral approach group were 3.20.There is better improvement of gait in posterior approach group than the lateral approach group, eventhough it is not statistically significant (P value:0.711).

\section{Rivermead Visual Gait Score At 3 Months Post Op}

\begin{tabular}{|l|l|l|l|l|l|l|}
\hline & & & & & Std. & \\
\hline $\begin{array}{l}\text { Rivermead } \\
\text { visual gait }\end{array}$ & Group & $\mathbf{N}$ & Mean & $\begin{array}{l}\text { Std. } \\
\text { Deviation }\end{array}$ & Error & $\begin{array}{l}\text { T-Test } \\
\text { P Value }\end{array}$ \\
\hline score at 3 & & & & & Mean & \\
\hline months post & & & & & .711 \\
\cline { 2 - 7 } op & Posterior & 10 & 2.50 & 5.276 & 1.668 & .727 \\
\cline { 2 - 6 } & Lateral & 10 & 3.20 & 2.616 & .827 & \\
\hline
\end{tabular}

Functional outcome were assessed postoperatively in both the lateral surgical approach group patients and posterior surgical approach group patients using the Harris Hip Score system ${ }^{[34]}$.Among the posterior approach group patients $30 \%$ of patients had excellent outcome, $60 \%$ of patients had good outcome, $10 \%$ had poor outcome. Among the lateral approach group patients $20 \%$ of patients had excellent outcome, $60 \%$ of patients had good outcome, $20 \%$ had fair outcome. Among the excellent outcome patients $60 \%$ of the patients 
were posterior approach group. Patients from the posterior approach group had better functional outcome than the lateral approach group patients, eventhough it is not statistically significant (P value:0.362).

\section{Harris Hip Score at 3 months post op}

\begin{tabular}{|c|c|c|c|c|c|c|}
\hline & \multicolumn{2}{|l|}{ Group } & \multirow[t]{2}{*}{ Total } & \multirow[t]{2}{*}{$\begin{array}{l}\text { Pearson Chi- } \\
\text { Square Tests } \\
\text { P value }\end{array}$} \\
\hline & & & Posterior & Lateral & & \\
\hline \multirow{12}{*}{$\begin{array}{l}\text { Harris Hip Score } \\
3 \text { month post op }\end{array}$} & \multirow[t]{6}{*}{ Excellent } & Count & 3 & 2 & 5 & \\
\hline & & $\begin{array}{ll}\% & \text { withi } \\
\text { excellent }\end{array}$ & $160.0 \%$ & $40.0 \%$ & $100.0 \%$ & \\
\hline & & $\%$ within Group & $30.0 \%$ & $20.0 \%$ & $25.0 \%$ & \\
\hline & & Count & $\frac{6}{500 m}$ & $\frac{6}{60 m-19}$ & & \\
\hline & & $\%$ within good & $50.0 \%$ & $50.0 \%$ & $100.0 \%$ & \\
\hline & & $\%$ within Group & $60.0 \%$ & $60.0 \%$ & $60.0 \%$ & \\
\hline & \multirow{3}{*}{ Fair } & Count & 0 & 2 & 2 & \\
\hline & & $\%$ within fair & $.0 \%$ & $100.0 \%$ & $100.0 \%$ & \\
\hline & & $\%$ within Group & $.0 \%$ & $20.0 \%$ & $10.0 \%$ & \\
\hline & \multirow{3}{*}{ atPoor } & Count & 1 & 0 & 1 & \\
\hline & & $\%$ within poor & $100.0 \%$ & $.0 \%$ & $100.0 \%$ & \\
\hline & & $\%$ within Group & $10.0 \%$ & $.0 \%$ & $5.0 \%$ & \\
\hline
\end{tabular}

Complications were assessed intraopreratively and postoperatively in both the lateral surgical approach group patients and posterior surgical approach group patients. Among the lateral approach group patients $30 \%$ of patients developed trendelenburg test positive and none of the posterior approach group patients had trendelenburg test positive. one patient had posterior dislocation in the posterior approach group patients but no dislocation were encountered in the lateral approach group patients.

\section{Complications}

\begin{tabular}{|c|c|c|c|c|c|c|}
\hline & \multirow[b]{3}{*}{ Count } & \multicolumn{2}{|l|}{ Group } & \multirow[t]{2}{*}{ Total } & \multirow{2}{*}{$\begin{array}{l}\text { Pearso n } \\
\text { Chi- Square } \\
\text { Tests } \\
\text { P value }\end{array}$} \\
\hline & & & Posterio $r$ & Lateral & & \\
\hline \multirow[t]{9}{*}{ Com plicat ion } & \multirow[t]{3}{*}{ Nil } & & 9 & 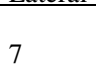 & 16 & \\
\hline & & $\% \quad$ within & $56.3 \%$ & $43.8 \%$ & $100.0 \%$ & \multirow{8}{*}{0.119} \\
\hline & & $\%$ within Group & $90.0 \%$ & $70.0 \%$ & $80.0 \%$ & \\
\hline & \multirow{3}{*}{$\begin{array}{l}\text { Trendelenburg } \\
\text { test Positive }\end{array}$} & Count & 0 & 3 & 3 & \\
\hline & & $\% \quad$ within & $.0 \%$ & $100.0 \%$ & $100.0 \%$ & \\
\hline & & $\%$ within Group & $.0 \%$ & $30.0 \%$ & $15.0 \%$ & \\
\hline & \multirow{3}{*}{$\begin{array}{l}\text { Posterior } \\
\text { dislocation }\end{array}$} & Count & 1 & 0 & 1 & \\
\hline & & $\% \quad$ within & $100.0 \%$ & $.0 \%$ & $100.0 \%$ & \\
\hline & & $\%$ within Group & $10.0 \%$ & $.0 \%$ & $5.0 \%$ & \\
\hline
\end{tabular}

\section{Discussion}

Surgical exposure is fundamental to the end result in hip arthroplasty.

In total hip arthroplasty ,many surgical approachescan be used. The two most commonly used approaches are "the posterior ${ }^{[23]}$ and the lateral (Modified Hardinge type) ${ }^{[33]}$ approaches".

These two approaches were studied because they are the two most frequently performed approaches and they provide goodsurgical exposure for total hip arthroplasty. Although several studies have been done to compare the merits of these two approaches, no study has been able to demonstrate the superiority of one over the other.

The issues involved in selecting a surgical approach are addressed in this study. Woo (1982) ${ }^{[38]}$; Paterno (1997); Li(1999)reported-“" The posterior approach is generally considered to be easy to perform, using 
less extensive tissue dissection, which gives shorter operation times, and less blood loss. It allows a good exposure of the femur that may reduce the risk of femoral fracture during the procedure. It is considered to be associated with less problems with gait since the abductor muscles are not dissected. However, it is often more difficult to see the acetabulum and increased rates of dislocation have been reported. It also has higher incidences of sciatic nerve injury and femoral stem loosening."

In our prospective study of both the approaches, it was found that the operative time and blood loss to favour posterior group, eventhoughblood loss was statistically insignificant, operative time shows statistical significance. The advantages of the lateral approach are that it provides adequate exposure of both proximal femur and acetabulum ${ }^{[39]}$, thereby allowing proper acetabular cup positioning and decreased incidence of hip dislocation ${ }^{[40,41]}$. There is also decreased incidence of sciatic nerve injury, because the nerve is away from the surgical field and also preserves the posterior joint capsule. However, the disadvantages are that there are increased chances for the superior gluteal nerve ${ }^{[42,43]}$ and the gluteus medius muscle to get injured. This may result in delayed recovery of strength of the abductor musculature and cause Trendelenburg gait.

Schuhand Zieler ${ }^{[44]}$ reported - "abductor muscle avulsions were present in $3.5 \%$ of 372 patients after primary total hip arthroplasty.Total hip arthroplasty through lateral or anterolateral approach is popular in Europe and North America. Transgluteal approaches necessitate violation of the trochanteric attachment of the hip abductors. Although avulsion of hip abductors following hip arthroplasty is not common, it is nonetheless a debilitating condition. It can give rise to intractable pain, limp, inefficient gait pattern and lead to instability of hip and tiredness."

Our study assessed gait visually using the Rivermead visual gait assessment form for comparing the gait following total hip replacement. Though there is a more improvement in the posterior group compared to the lateral, which is statistically insignificant.

Miozzari HH, Dora C, Clark JM, Nozzle HP $\left(2010{ }^{[45]}\right.$ reported- "Trans-osseous repair using nonabsorbable sutures to reattach the abductor mechanism to the greater trochanter seems to be the favoured option." In our study abductor muscles were reattached to the greater trochanter using non-absorbable braided sutures.

The main aim of total hip arthroplasty is to improve the function and decrease pain. Barber ${ }^{[46]}$ in 1996 compared " 28 total hip replacement operated on using the posterior approach versus 21 hips using the direct lateral approach. Uncemented implants were used in both approaches. At 2 years follow-up, one hip dislocation was recorded in posterior approach group due to retroverted acetabular version. A Trendelenburg test as well as a limp score and an abductor power score were recorded without significant differences between groups. This is the only study which assessed Harris hip score and found both groups improved their postoperative score to obtain the same mean score of 94 at the end of 2 years and found it is not significant."

In this study we used Harris hip score to evaluate the postoperative outcome. We assessed at the end of 3 months for comparing the early functional outcome between the lateral and posterior approaches. Though there is a significant improvement in the overall functional outcome in posterior approach group, it is of doubtful significance.

Mullikenet al. ${ }^{[47]}$ (1998)-“ review of 770 total hip replacements via the lateral approach, found a $10 \%$ incidence of moderate or severe limp at 2 years, but there was no comparative posterior approach group."

Baker and Bitounis (1989) ${ }^{[42]}$ _“ found more positive postoperative Trendelenburg tests after the lateral approach than after the posterior one and considered that this weakness was due to detachment of the gluteal flap, although they did not quantify abductor strength." Ramesh et al. ${ }^{[48]}$ 1996, Baker and Bitounis 1989 reported "violation of the 'safe zone' (Comstock et al. 1994) ${ }^{[49]}$ within $5 \mathrm{~cm}$ of the greater trochanter may damage the superior gluteal nerve and thus further risk of abductor muscle weakness ${ }^{[46]}$."

However, as Kenny et al. ${ }^{[50]}$ (1999) found " the role of nerve injury in the production of postoperative abductor weakness is not clear as EMG evidence of acute nerve injury does not correlate with the clinical findings of weak abduction."

Baker $^{[42]}(1989)$, Barber ${ }^{[46]}(1996)$ and Downing ${ }^{[51]}(2001)$ studied "The presence of a postoperative Trendelenburg gait and found no significant difference between posterior versus direct lateral surgical approach."

In our prospective study of both the approaches, it was found that 3 patients in lateral approach group had trendelenburg test positive and whereas none in the posterior approach had it positive. The postoperative 
Trendelenburg test seems to favour posterior group but this is statistically insignificant.

Baker ${ }^{[42]}(1989)$ and Weale ${ }^{[52]}$ (1996) studied Nerve palsy or injury and compared "22 participants operated on by the posterior approach to 20 operated on by the direct lateral one. Incidence of nerve injury (sciatic, obturator, femoral nerves) was reported at 4 weeks from operation. He used electromyographic study. Baker observed only superior gluteal nerve palsies. A significant difference between posterior versus direct lateral surgical approach was found in favour of less nerve injuries with the posterior approach However, when looking at each type of nerve palsy separately, no significant difference was found between each type of surgical approach."

Downing ${ }^{[51]}(2001)$ compared "49 total hip arthroplasties done by theposterior approach versus 51 hips by the direct lateral approach for 100 participants. All participants had cemented stems, but the type was different in each group. Follow-up was done at 3 and 12 months. Twenty seven participants were lost to followup. Four participants had a hip dislocation, $1 / 49(2.0 \%)$ in the posterior approach group versus $3 / 51(5.9 \%)$ in the direct lateral approach group. The difference was not statistically significant between the groups. Trendelenburg tests were reported at 12 months from surgery without difference between groups."

In our study group complications were assessed intra operatively and postoperatively in both the lateral surgical approach group and

posterior surgical approach group. One patient had posterior dislocation in the posterior approach group but no dislocations were encountered in the lateral approach group. On analysing the cause for dislocation it was found that dislocation was due to the retroverted acetabular cup (5 degree of retroversion).This complication can be prevented by stabilising the patient in proper lateral position with pubic support, identifying the transverse acetabular ligament(TAL) and using the TAL as a guide for acetabular cup placement. The acetabular component is aligned parallel to the plane between the TAL and the acetabular labrum and the results showed a very low rate of dislocation. The acetabular cup is too anteverted, if the bone and TAL is well seen anteriorly, cup is retroverted if the TAL is not seen anteriorly and bone is seen posteriorly.

Callanan et al. ${ }^{[53]}$ reported that "The orientation of the acetabular cup in a primary THA is important to low dislocation rates, liner fracture, and wear. While several studies suggest optimal orientation ranges, most indicate acceptable anteversion from 0 to 30 degree and acceptable inclination from 30 to 50 degree. Cup angles that stray outside the optimal ranges are linked to those complications, the most common being dislocation of the prosthesis. Dislocations affect an estimated 1\% to 5\% of THAs performed. Cup orientations that fall within the acceptable ranges have much lower incidence of all types of dislocations. High angles of inclination (55-69) are linked to higher rates of dislocation and recurrent dislocations. Highly anteverted cups correlate with an increased incidence of anterior dislocation while retroverted cups correlate with an increased risk of posterior dislocation. A commonly used range of acceptable angles is the safe zone established by Lewinnek et al. ${ }^{[29]}$ (5-25 degree of anteversion and 30-50 degree of abduction), which is based on an increased dislocation risk for angles outside of these ranges.

Archbold et al ${ }^{[54]}$ recommended "a technique in which the acetabular component is aligned parallel to the plane between the TAL and the acetabular labrum and their results showed a very low rate of dislocation. However, in this study no assessment of post-operative acetabular component orientation was made."

In our prospective study of both the approaches, it was found that the acetabular cup version and inclination slightly seems to favour posterior group but this is statistically insignificant.

Limb length discrepancy, vertical and horizontal offset, If not corrected during total hip replacement can adversely affect the functional outcome of the surgery. Conventional methods of intraoperative limb length measurement are based on the distance between 2 reference points marked on the pelvis and femur. Charnley et al. (1979) ${ }^{[55]}$ reported- "The greater trochanter is used as an intraoperative landmark for leg-length assessment."

The location of the reference point on the pelvis varies in each case. The reference can be iliac fixation pins, intra operative callipers, infracotyloid pins, and fixed suture lengths. Della Valle CJ et al. ${ }^{[56]}$ reported that-"For these devices to work properly, the operating table must be level with the floor and the position of the hip must be reproduced precisely in all planes before and after reconstruction is performed".

In our study, in the posterior approach group intraoperative limb length measurements were assessed using fixed suture length method. In the posterior approach group, $30 \%$ of the patient had release of the gluteus maximus insertion to obtain normal horizontal offset, This was assessed intraoperatively using the piriformis attachment in the piriformis fossa as a guide. We were able to get better limb length correction, verticle offset and Horizontal offset in posterior approach group than lateral approach group. 


\section{Limitations}

There are a few limitations in our study namely

1. It is not randomized and not double blinded.

2. Sample size is small.

3. Selection bias - patients in both groups are not matched.

4. Short term follow up.

\section{Conclusion}

According to our study, equally good results can be obtained in total hip replacement surgery using either the lateral approach or the posterior approach. The good results in both the groups may be due to the experience of the surgeons who performed their usual approach. In this study the functional outcome, Radiological outcome and gait are equally good in both lateral and posterior approach.

It was observed that fixed suture method in the posterior approach group was able to achieve excellent vertical femoral offset and correction of limb length discrepancy. Likewise, malpositioning of the acetabular cup can be prevented by using the transverse acetabular ligament (TAL) as a guide for acetabular cup placement.

Postoperative abductor weakness has many causes and we believe good surgical technique and awareness of the anatomy of the nerve supply are key factors in preserving good abductor strength.

\section{Case : 1}

46 years male presented with fracture neck of femur Rt. Underwent uncemented total hip arthroplasty through posterior approach.

Duration of surgery

Blood loss

Harris Hip Score

score at 3 months

discrepancy(LLD):

Pre operative X-Ray

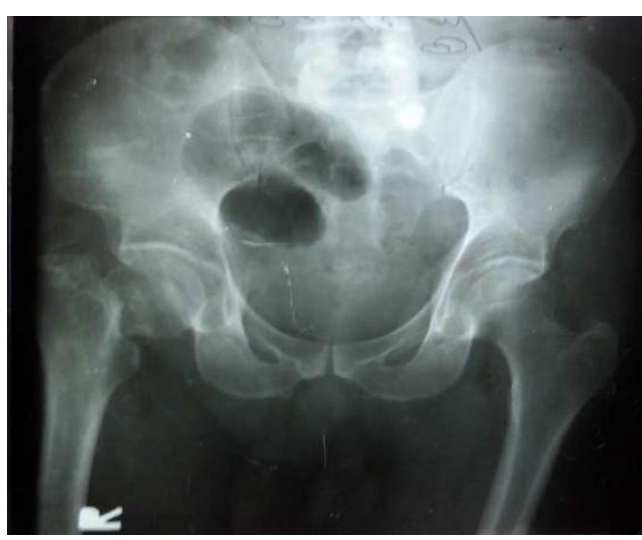

Acetabular Inclination-42*

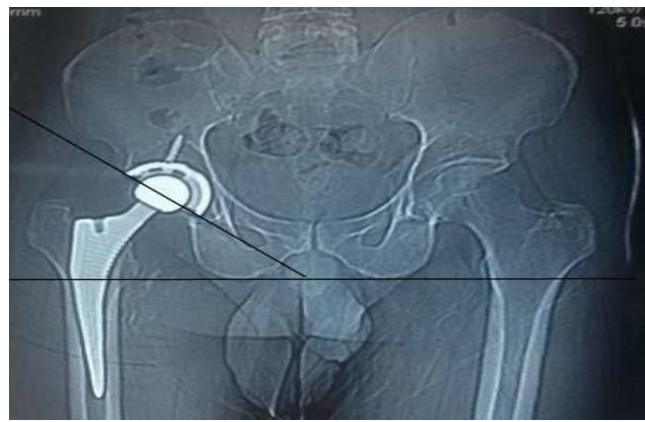

Pre operative shortening- $1.2 \mathrm{~cm}$

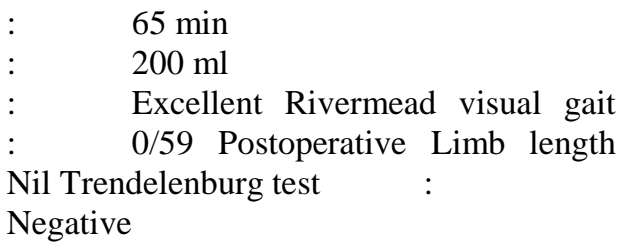

Post operative X-Ray

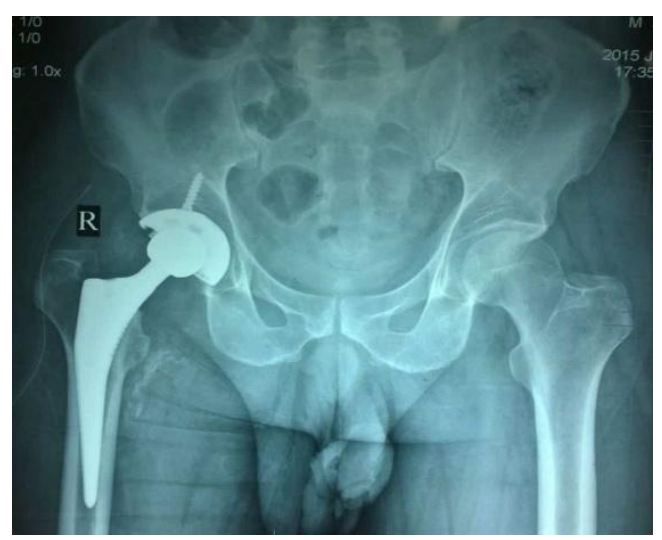

Acetabular version-21*

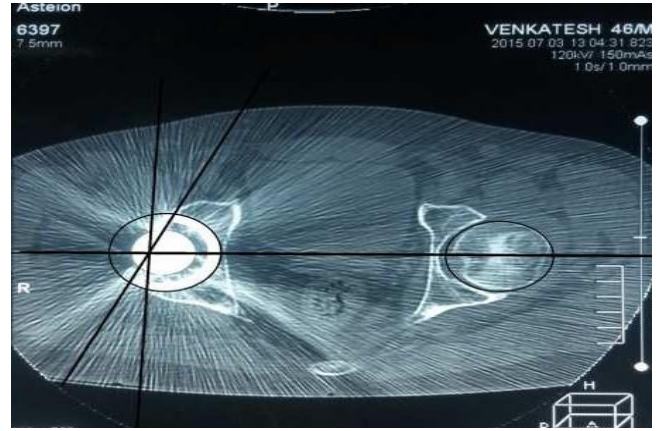

Post operative LLD-Nil 

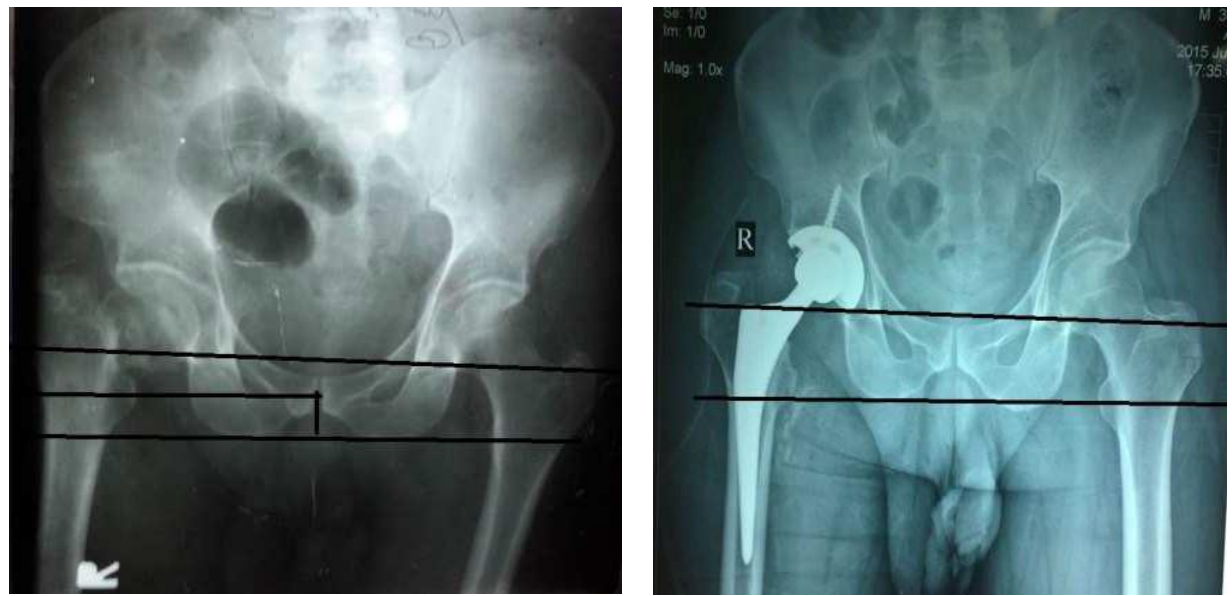

Post operative Horizontal and vertical offset ratio:1

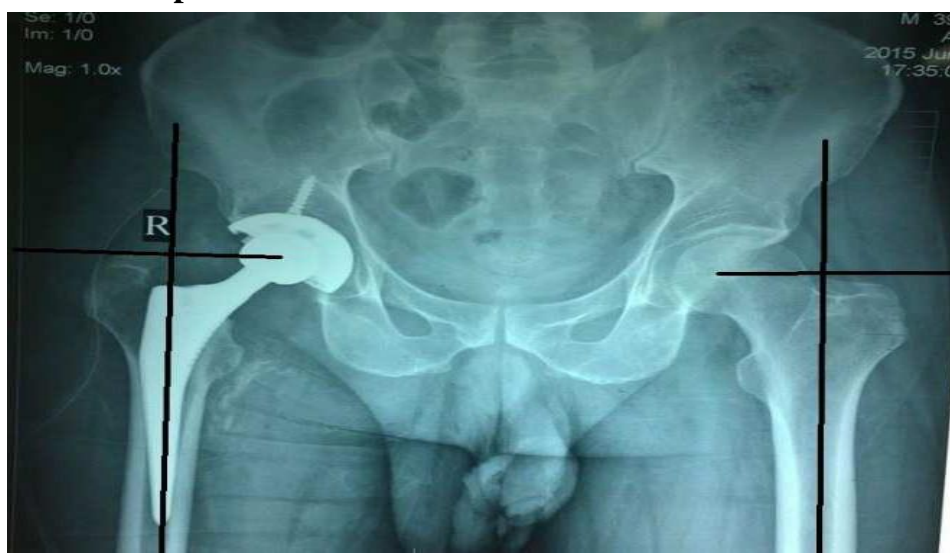

Patient position Intraoperative pictures
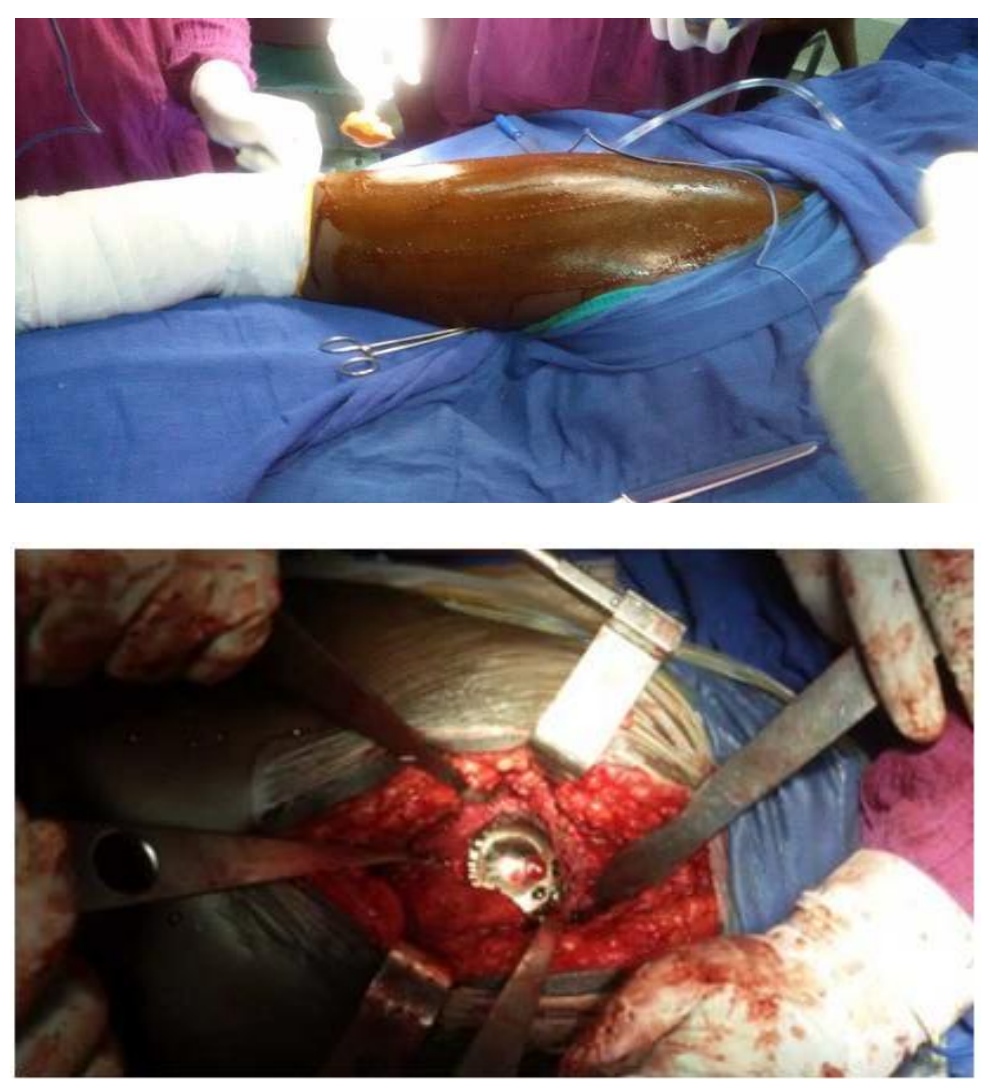

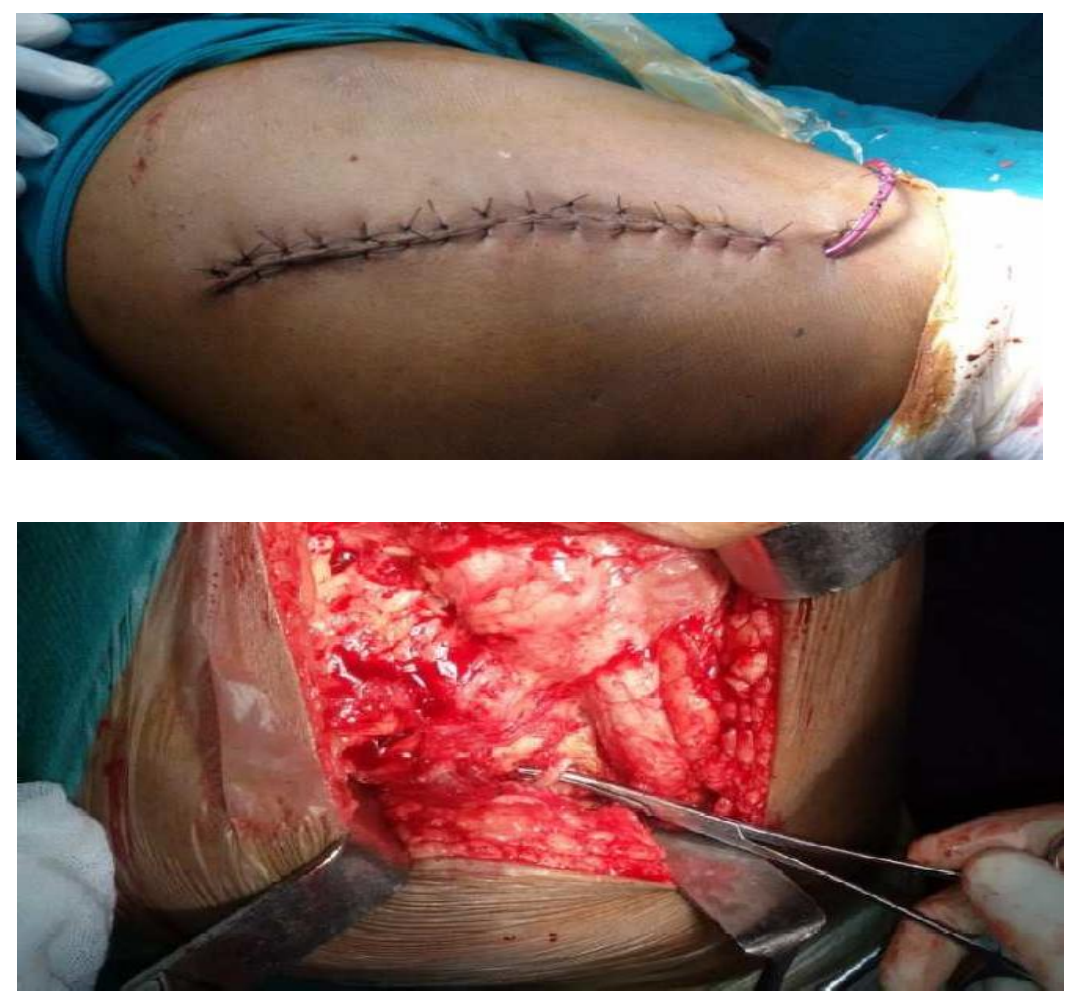

Case: 2

43 years male fracture neck of femur Lt.underwent uncemented total hip arthroplasty through posterior approach.

Duration of surgery

Blood loss

Harris Hip Score

Rivermead visual gait score at 3 months shortening

Postoperative Limb length discrepancy

Trendelenburg test

Pre operative $x$-Ray

Post operative X-Ray

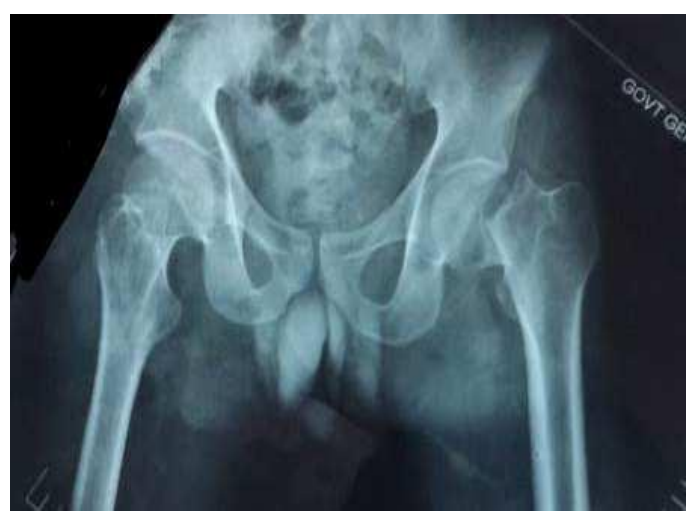

Acetabular inclination : 45*
$75 \mathrm{~min}$

$220 \mathrm{ml}$

Excellent

$0 / 59$

$1 \mathrm{~cm}$

Nil

Negative
Preoperative

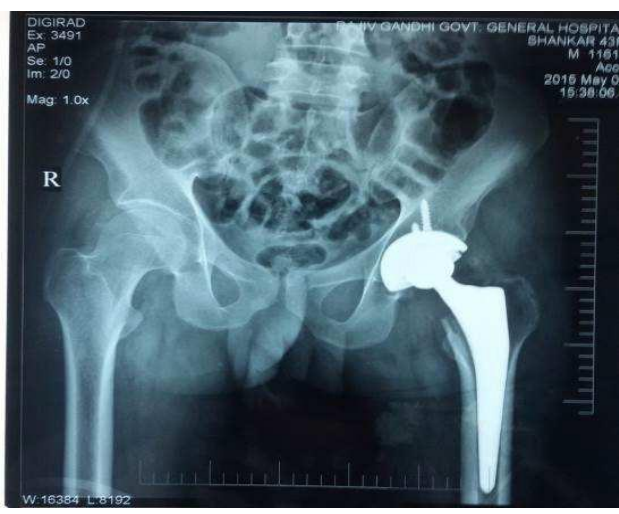

Acetabular version:22* 

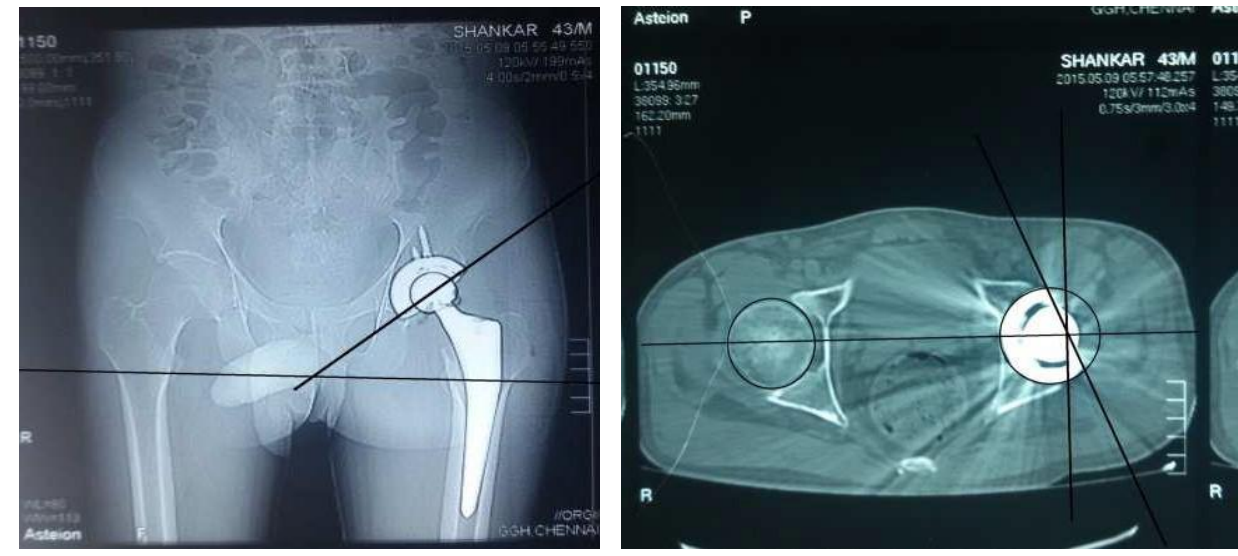

Horizontal offset Ratio and Verticle Offset Ratio:1

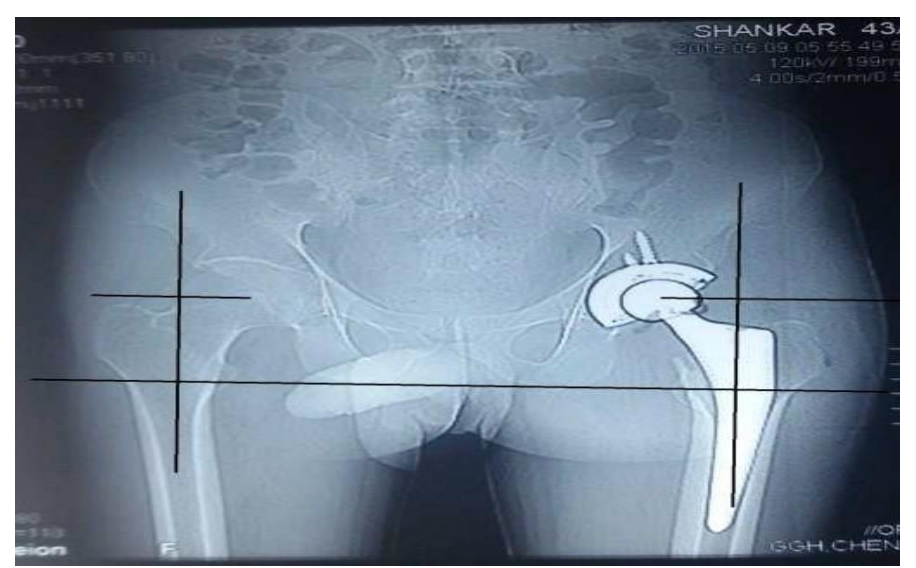

ntraoperative pictures
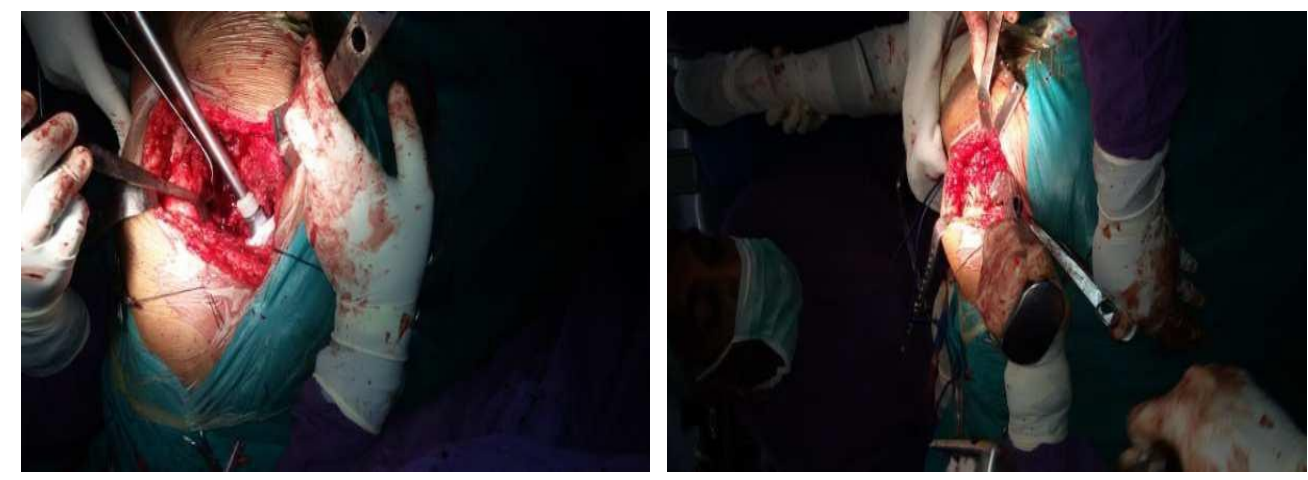

Clinical pictures
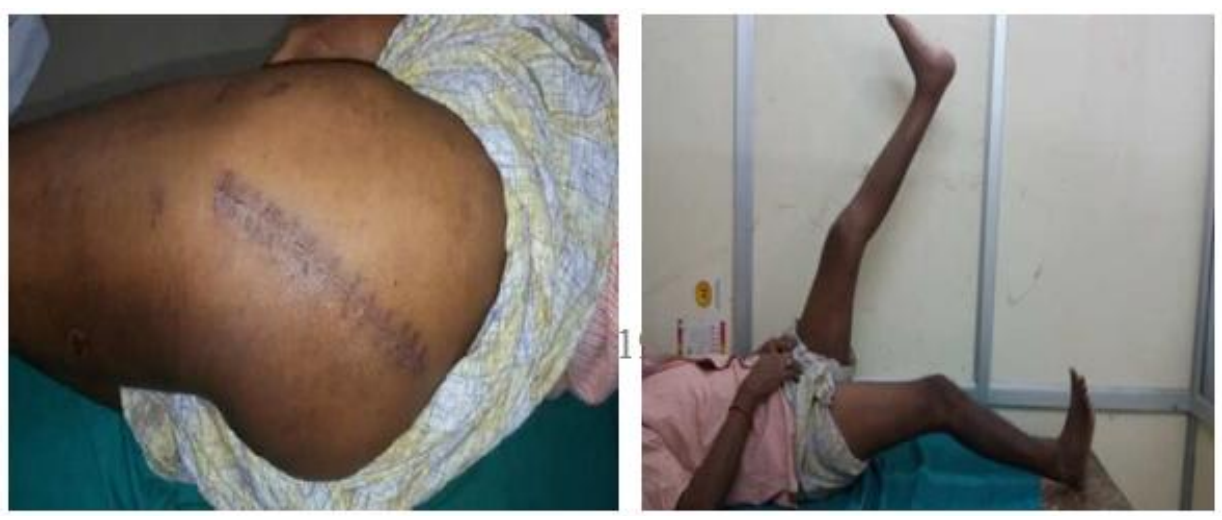


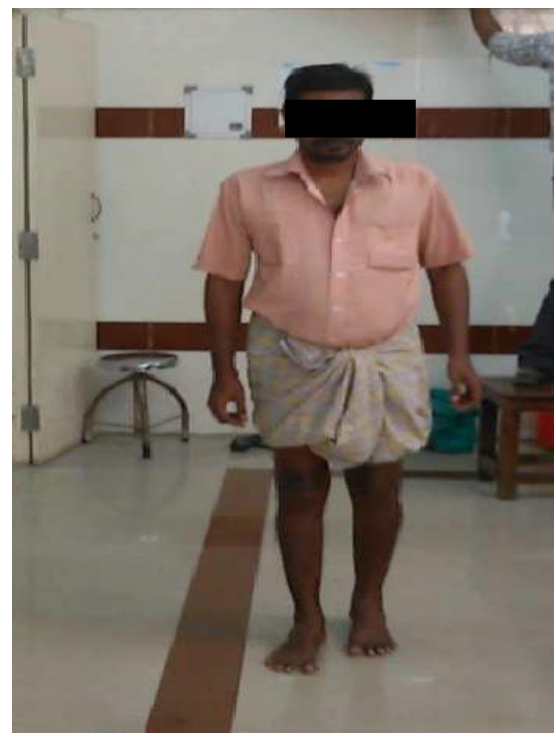

Case : 3

27years male presented with chronic arthritis Rt. hip underwent uncemented total hip arthroplasty through lateral approach.

Duration of surgery

Blood loss

Harris Hip Score

Rivermead visual gait score at 3 months shortening

Postoperative Limb length discrepancy

shortening

Trendelenburg test

$110 \mathrm{~min}$

$300 \mathrm{ml}$

Excellent

$5 / 59$

$0.8 \mathrm{~cm}$

$0.5 \mathrm{~cm}$ of

Negative
Pre operative x-Ray

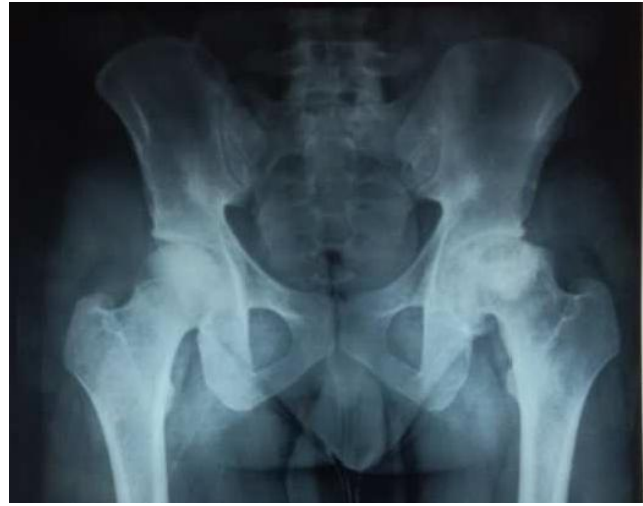

Acetabular inclination-48*

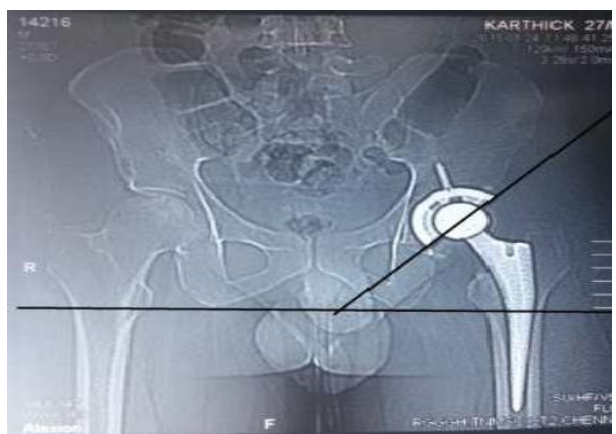

Horizontal offset Ratio:1,Verticle Offset Ratio:1.05
Post operative X-Ray

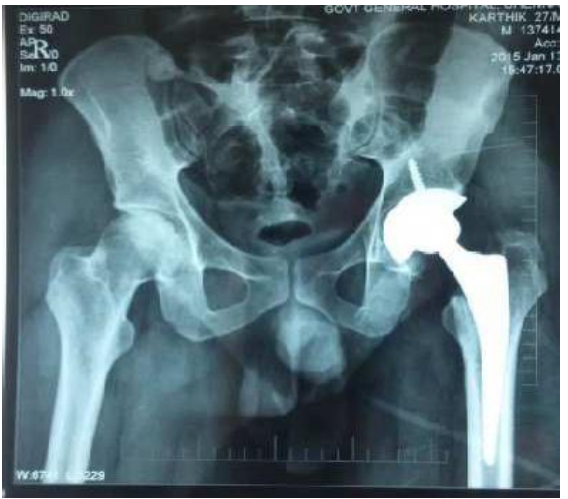

Acetabular version:16*

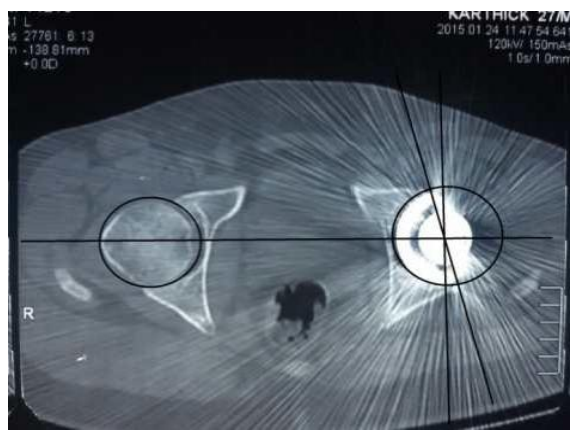

Preoperative 


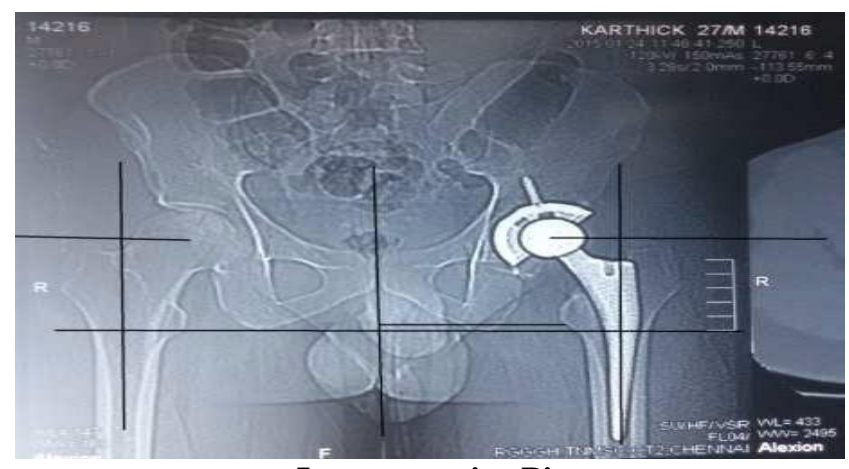

Intraoperative Pictures

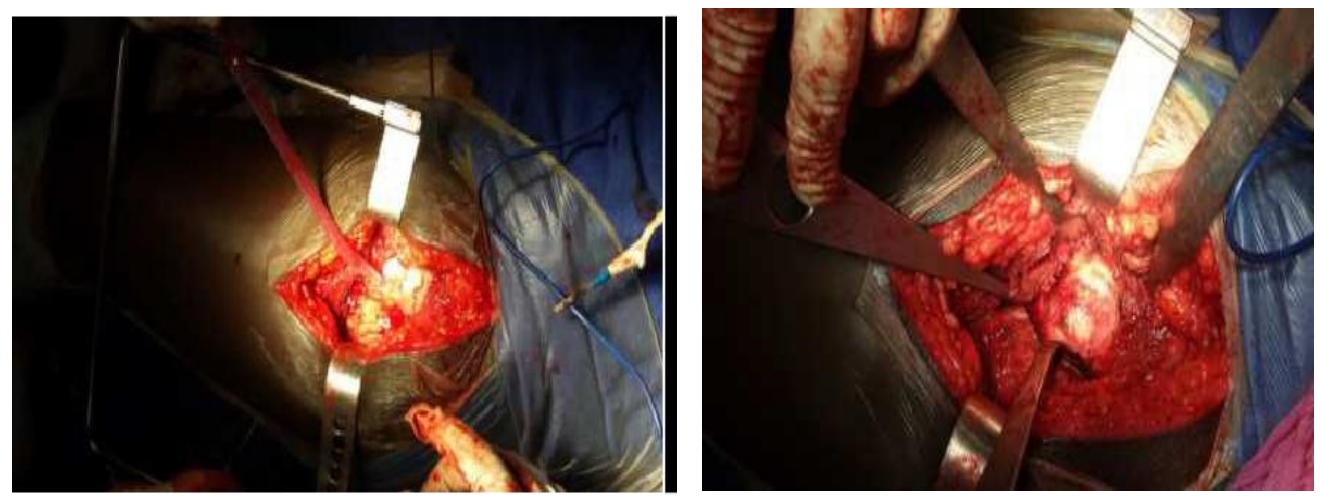

Post operative scar

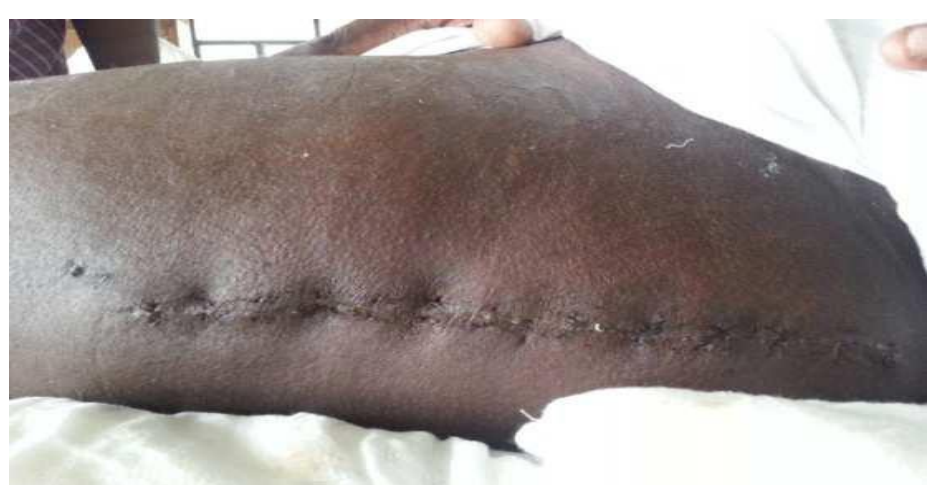

Clinical pictures

Case : 4
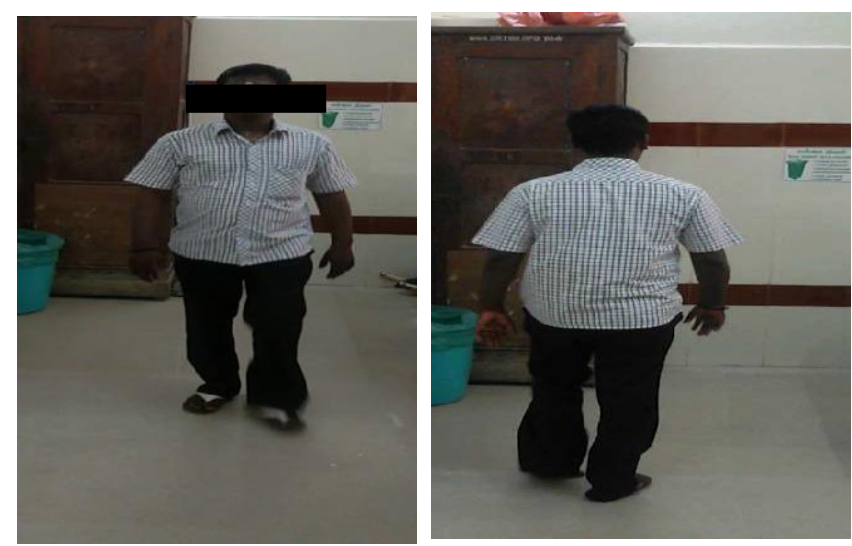

60 years male presented with fracture non-union neck of femur Rt. underwent uncemented total hip arthroplasty through 
lateral approach.

Duration of surgery

$110 \mathrm{~min}$

Blood loss

Harris Hip Score

Rivermead visual gait score at 3 months shortening

$350 \mathrm{ml}$

Good

$6 / 59$

$2.3 \mathrm{~cm}$

Postoperative Limb length discrepancy

Nil

Trendelenburg test

Positive

Preoperative X-Ray

Postoperative X-Ray

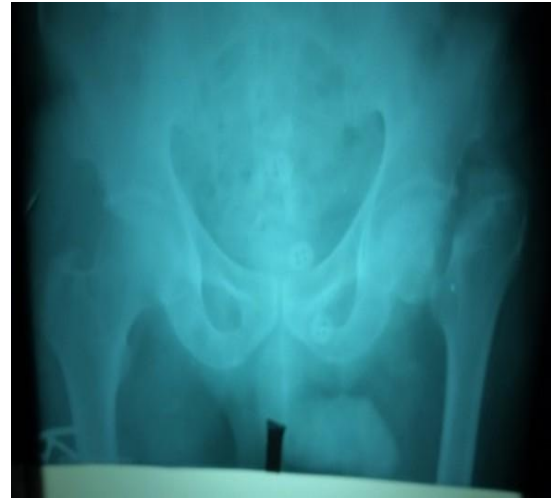

Acetabular inclination :38*

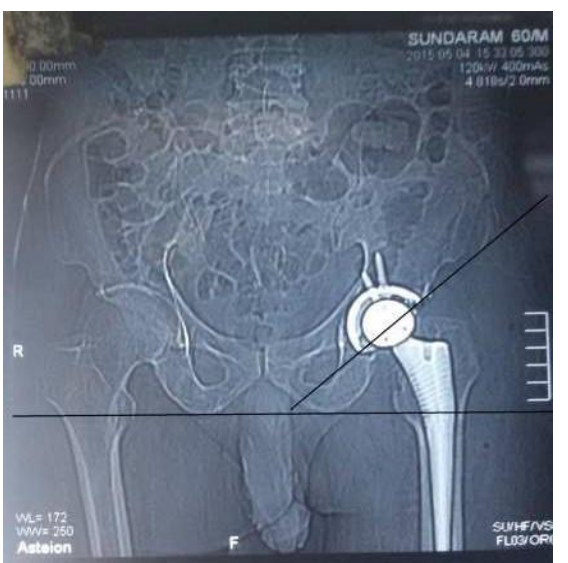

Horizontal offset Ratio and Verticle Offset Ratio:1

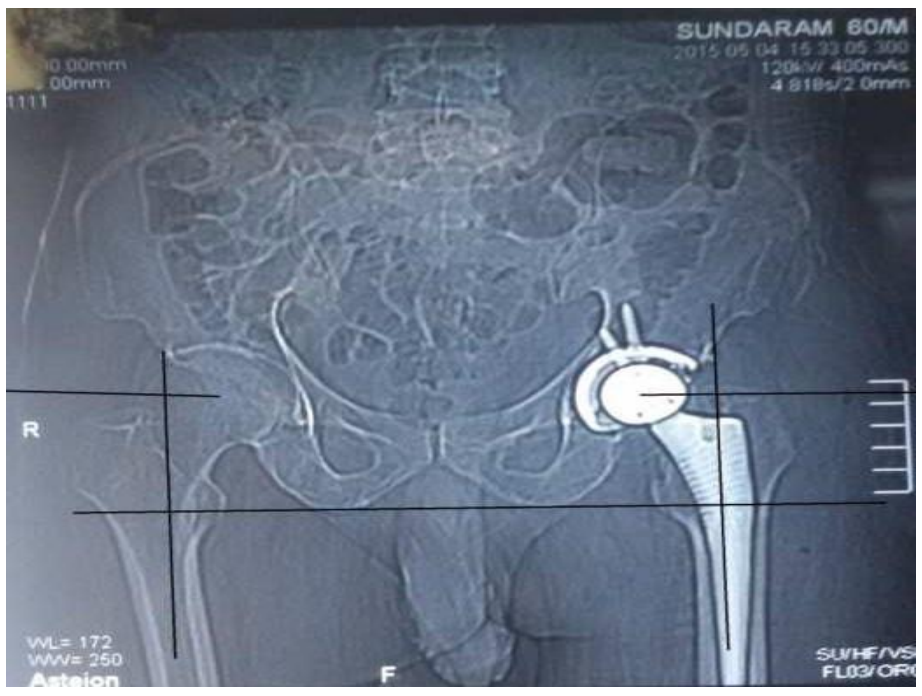

Preoperative

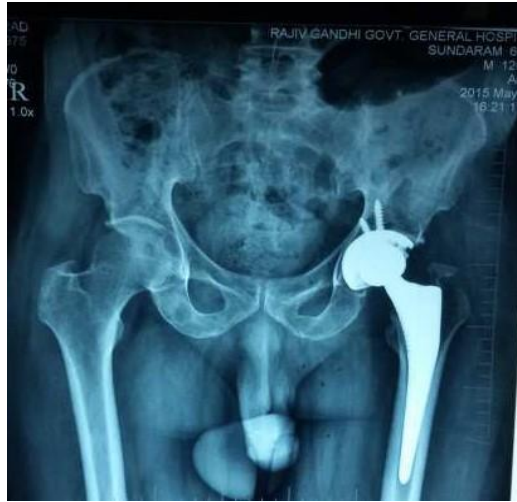

Acetabular version:31*

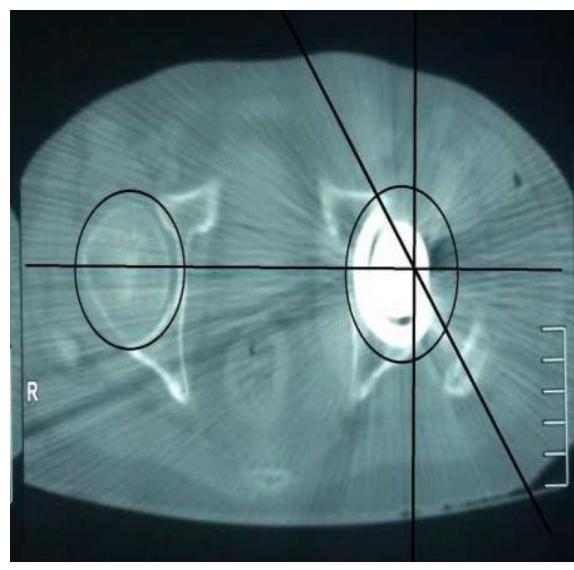




\section{Clinical pictures}
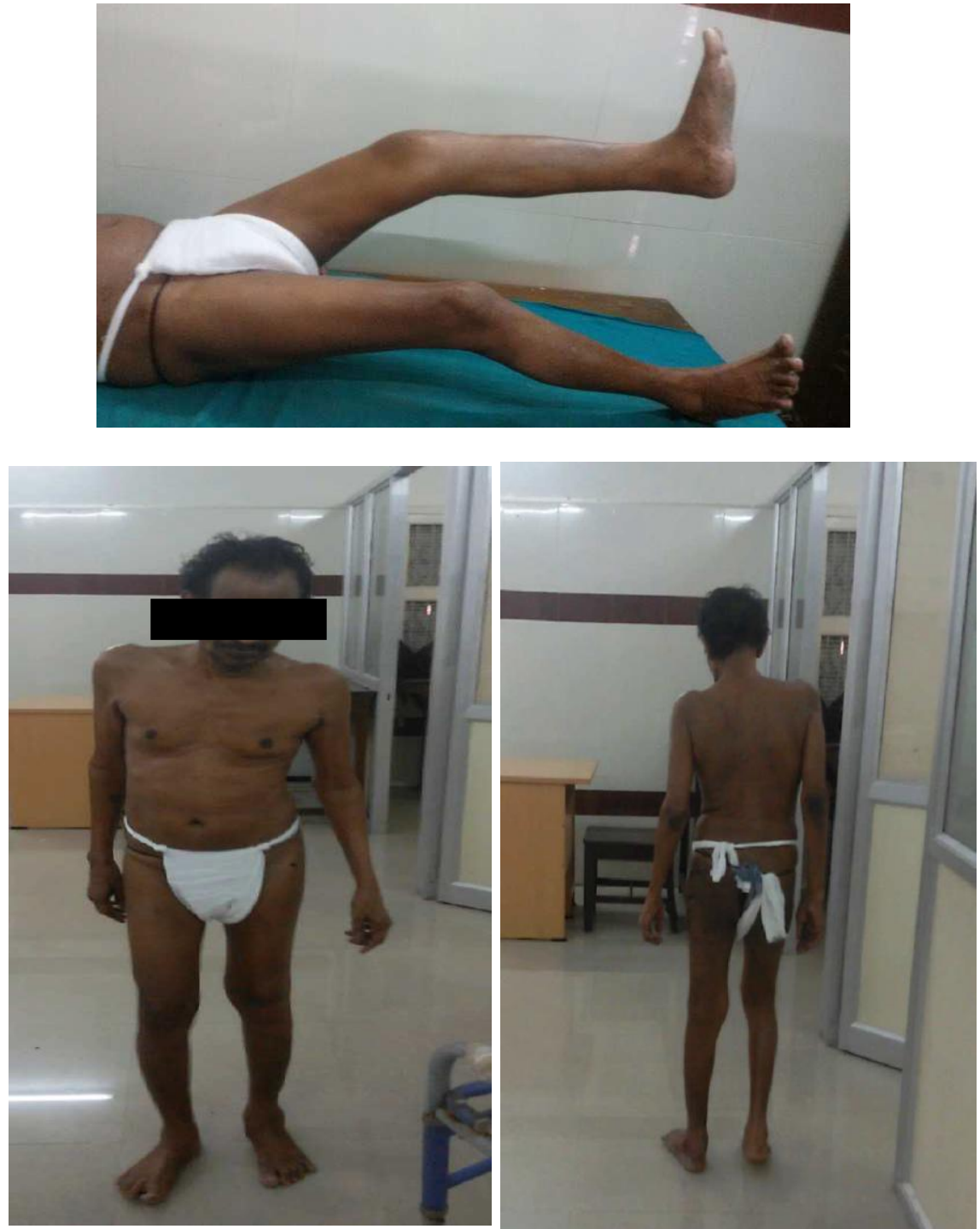

\section{BIBLIOGRAPHY}

[1]. PauwelsF.Gesamme / teAbhand / ungenzur funktionellen Anatomie Berlin : Springer Verlag, 1965. Translation with additions : Biomechanics of the locomotor apparatus. Berlin : Springer Verlag, 1980.

[2]. Pauwels F. 1976. Biomechanics of the normal and diseased hip: Theoretical foundation, technique and results of treatment. Berlin: Springer-Verlag.

[3]. S. Zimmera, W. G. Hawkes, J. I. Hudson et al, "Outcomes of surgical management in patients aged 65 years and older: cemented versus cementless femoral compoments and lateral or anterolateral versus posterior anatomical approach,” J. Orthop. Res, vol. 20(2), pp. 182-191,2002.

[4]. Smith-Petersen MN: Approach to and exposure of the hip joint for mold arthroplasty, J Bone Joint Surg 31A:40, 1949

[5]. Smith-Petersen MN. Evolution of mould arthroplasty of hip joint. J Bone Joint Surg Br 1948; 30:59-75.

[6]. Judet J, Judet R. The use of an artificial femoral head femoral head for arthroplasty of the hip joint. J Bone Joint Surg Br 1950; 32:166-173.

[7]. Rang M. Anthology of Orthopaedics. Edinburgh, London, New York: Churchill Livingstone; 1966.

[8]. Wiles P. The Surgery of the osteo-arthritic hip. Br J surg. 1957;45:488-497.

[9]. McKee GK and Watson-Farrar J, Replacement of arthritic hips by the McKee-Farrar prosthesis. J Bone Joint Surg [Br] 1966; 48: 245-59.

[10]. Ring PA, Complete replacement arthroplasty of the hip by the ring prosthesis. J Bone Joint Surg Br 1968;50: 720-31.

[11]. Charnley, J. : Total hip replacement by low friction arthroplasty. Internal Publication No. 23. Centre for Hip Surgery. Wrightington Hospital. January 1970

[12]. Charnley J. Low Friction Arthroplasty of the Hip - Theory and Practice. Berlin: Springer-Verlag; 1979.

[13]. Amstutz HC, Maki S. Complications of trochanteric osteotomy in total hip replacement. J BoneJoint Surg[Am] 1978; 60-A

[14]. : :214-6.

[15]. Muller ME. Total Hip replacement: Planning Technique and Complications In: Surgical Management of Degenerative arthritis of the Lower Limb. Heidelberg: Lea and Febiger; 1975,

[16]. McFarland B, Osborne G: Approach to the hip: A suggested improvement on Kocher's method. J Bone Joint Surg 36B:364- 271, 1954. 
[17]. Hardinge K. The direct lateral approach to the hip. J Bone Joint Surg Br 1982;64-B:17-9.

[18]. Dall.D. Exposure of the hip by anterior osteotomy of the greater trochanter: a modified anterolateral approach. J Bone Joint Surg [Br] 1986;68-B:382-6.

[19]. Learmonth ID, Allen PE. The Omega Lateral Approach to the hip .J Bone Joint Surg [Br] 1996;78-B:559-61.

[20]. Watson-Jones R: Fractures of the neck of the femur, Br J Surg 23:787, 1935-1936.

[21]. Langenbeck, 1874. Langenbeck B von: Über die Schussverletzungen des Huftgelenks. Arch Klin Chir 1874; 16:263.

[22]. Kocher T. Chirurgische operationslehre, vol. 5. 5th edition.Jena, Germany7 Gustav Fischer; 1907

[23]. Gibson A. A posterior exposure of the hip. J Bone Joint Surg Br 1950;32:183-6.

[24]. Moore AT. In: American Academy of OrthopaedicSurgeons editor (s). Instructional Course Lectures. Vol. 16, St Louis: CVMosby, 1959.

[25]. Gore DR, Murray SP, Sepic SB, Gardner GM: Anterolateral compared to posterior approach in total hip arthroplasty: Difference in component positioning, hip strength, and hip motion. Clin Orthop 165:180-187, 1982

[26]. Roberts, J. M., Fu, F. H., McClain, E. J., and Ferguson,A. B., Jr.: A comparison of the posterolateral and anterolateral approaches to total hip arthroplasty. Clin. Orthop. 187:205, 1984.

[27]. Robinson, R. P., Robinson, H. J., Jr., and Salvati, E. A.: Comparison of the transtrochanteric and posterior approaches for total hip replacement. Clin. Orthop. 147:143, 1980.

[28]. Vicar, A. J., and Coleman, C. R.: A comparison of the anterolateral, transtrochanteric, and posterior surgical approaches in primary total hip arthroplasty. Clin. Orthop. 188: 152, 1984.

[29]. Ali Khan MA, Brackenbury PH, Reynolds IS. Dislocation following total hip replacement. J Bone Joint Surg Br. 1981;63:214-8.

[30]. Lewinnek, G. E.; Lewis, J. L.; Tarr, R.; Compere, C. L.; and Zimmerman, J. R.: Dislocations after total hip-replacement arthroplasties. J Bone Joint Surg Am. 1978;60(2): 217-20.

[31]. McGrory B J, Morrey B F, Cahalan T D, An K N, Cabanela M

[32]. E. Effect of femoral offset on range of motion and abductor muscle strength after total hip arthroplasty. J Bone Joint Surg (Br) 1995; 77 (6): 865-9.

[33]. Hardcastle P, Nade S. The significance of the Trendelenburg test. J Bone Joint Surg 1985;67-B:741-6.

[34]. Pai VS :Significance of the Trendelenburg test in total hip arthroplasty. Influence of lateral approaches.J Arthroplasty. 1996 Feb;11(2):174-9.

[35]. Frndak PA, Mallory TH, Lombardi Jr AV: Translateral surgical approach to the hip. The abductor muscle "split". Clin Orthop 295:135-141, 1993

[36]. Harris WH. Traumatic arthritis of the hip after dislocation and acetabular fractures: treatment by Mold arthroplasty. An end- result study using a newmethod of result evaluation. J Bone Joint Surg [Am] 1969;51-A:737-55.

[37]. Murray DW. The definition and measurement of acetabular orientation. J Bone Joint Surg [Br] 1993;75-B:228-232.

[38]. Olivecrona H, Weidenhielm L, Olivecrona L, et al. A new CT method for measuring cup orientation after total hip arthroplasty: a study of 10 patients. Acta Orthop Scand 2004;75:252-260.

[39]. Lord S.E, HalliganP.W, Wade D.T: Visual gait analysis:the development of a clinical assessment and scale.Clin Rehabil 1998; 12; 107

[40]. Woo RYG, Morrey BF. Dislocations after total hip arthroplasty. J Bone Joint Surg 1982;64-A:1295-306.

[41]. Hoppenfeld S, DeBoer P, Buckley R. Surgical exposures in orthopaedics: the anatomic approach.Philidelphia, PA: Lippincott Williams and Wilkins; 2009.

[42]. Masonis JL, Bourne R. Surgical approach, abductor function, and total hip arthroplasty dislocation. Clin Orthop Relat Res. $2002 ; 405: 46-53$.

[43]. Kwon MS, Kuskowski M, Mulhall K, et al. Does surgical approach affect total hip arthroplasty dislocation rates? Clin Orthop Relat Res. 2006;447:34-8.

[44]. Baker AS, Bitounis VC. Abductor function after total hip replacement .An electromyographic and clinical review. J Bone Joint Surg 1989;71- B:47-50.

[45]. Khan T, Knowles D. Damage to the superior gluteal nerve during the direct lateral approach to the hip: a cadaveric study. J Arthroplasty. 2007;22:1198-200.

[46]. Schuh A, Zeiler G (2003) Rupture of the gluteus medius tendon. Zentralbl Chir 128:139

Master chart for posterior approach in total hip arthroplasty

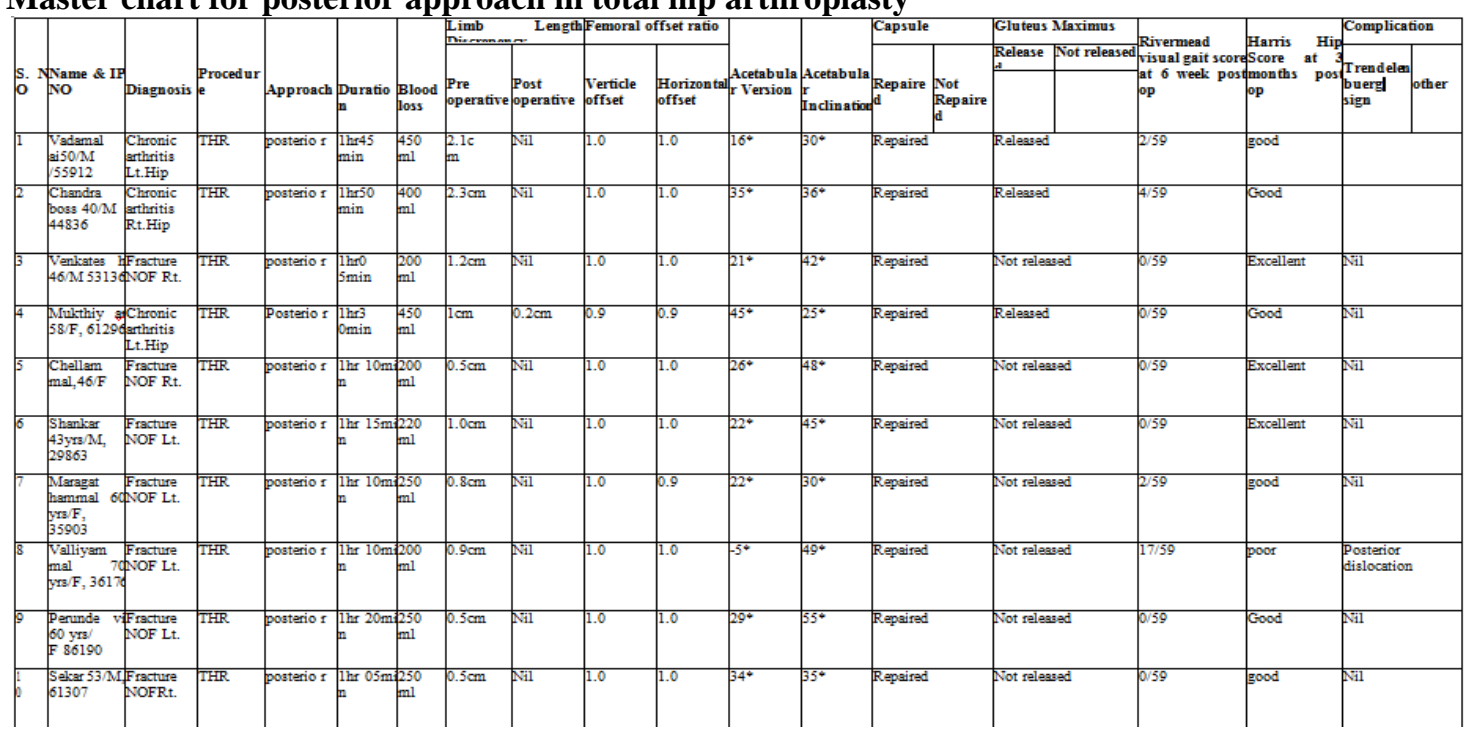




\section{Master chart for lateral approach in total hip arthroplasty}

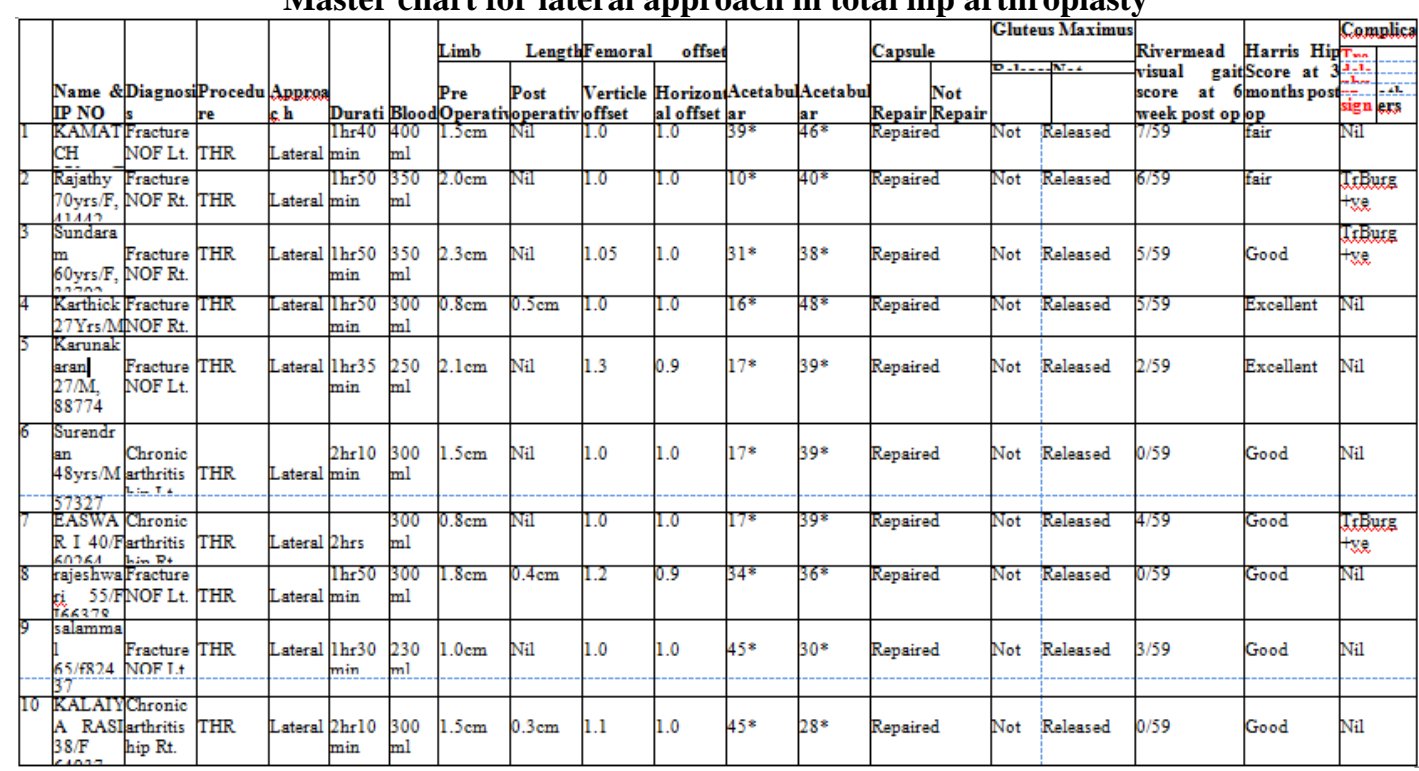

